\title{
In vitro extinction learning in Hermissenda: involvement of conditioned inhibition molecules
}

\author{
Joel S. Cavallo*, Brittany N. Hamilton and Joseph Farley \\ Program in Neuroscience, Department of Psychological and Brain Sciences, Indiana University, Bloomington, IN, USA
}

\section{Edited by:}

Martin Giurfa, Centre National de la Recherche Scientifique - Université Paul Sabatier-Toulouse III, France

\section{Reviewed by:}

Seth Davin Norrholm, Emory

University School of Medicine, USA

Etsuro Ito, Tokushima Bunri

University, Japan

*Correspondence:

Joel S. Cavallo, Department of Psychiatry and Behavioral

Neuroscience, University of Chicago, 5841 S. Maryland Avenue, MC 3077, Chicago, IL 60637, USA e-mail: jcavallo@uchicago.edu

\begin{abstract}
Extinction of a conditioned association is typically viewed as the establishment of new learning rather than the erasure of the original memory. However, recent research in the nudibranch, Hermissenda crassicornis (H.c.) demonstrated that extinction training (using repeated light-alone presentations) given $15 \mathrm{~min}$, but not $23 \mathrm{~h}$, after memory acquisition reversed both the cellular correlates of learning (enhanced Type B cell excitability) and the behavioral changes (reduced phototaxis) produced by associative conditioning (pairings of light, CS, and rotation, US). Here, we investigated the putative molecular signaling pathways that underlie this extinction in H.c. by using a novel in vitro protocol combined with pharmacological manipulations. After intact H.c. received either light-rotation pairings (Paired), random presentations of light and rotation (Random), or no stimulation (Untrained), B cells from isolated CNSs were recorded from during exposure to extinction training consisting of two series of 15 consecutive light-steps (LSs). When in vitro extinction was administered shortly $(2 \mathrm{~h}$, but not $24 \mathrm{~h}$ ) after paired training, B cells from Paired animals showed progressive and robust declines in spike frequency by the 30th LS, while control cells (Random and Untrained) did not. We found that several molecules implicated in H.c. conditioned inhibitory $(\mathrm{Cl})$ learning, protein phosphatase 1 (PP1) and arachidonic acid (AA)/12-lipoxygenase (12-LOX) metabolites, also contributed to the spike frequency decreases produced by in vitro extinction. Protein phosphatase 2B (PP2B) also appeared to play a role. Calyculin A (PP1 inhibitor), cyclosporin A (PP2B inhibitor), and baicalein (a 12-LOX inhibitor) all blocked the spike frequency declines in Paired B cells produced by 30 LSs. Conversely, injection of catalytically-active PP1 (caPP1) or PP2B (caPP2B) into Untrained B cells partially mimicked the spike frequency declines observed in Paired cells, as did bath-applied AA, and occluded additional LS-produced reductions in spiking in Paired cells.
\end{abstract}

Keywords: extinction, memory erasure, Hermissenda crassicornis, phosphatases, PP1, PP2B, arachidonic acid, 12(S)-HPETE

\section{INTRODUCTION}

After an association has been formed between a conditioned stimulus (CS) and an unconditioned stimulus (US), repeated presentations of the CS without the US result in the reduction of the conditioned response (CR), a process known as extinction (Pavlov, 1927). The reduction of the CR produced by extinction training is often only temporary, as evidenced by spontaneous recovery (Reviewed by Myers and Davis, 2002; see Sangha et al., 2003 for spontaneous recovery in the snail Lymnaea), or US-induced reinstatement of the extinguished CR (Rescorla and Heth, 1975). The fact that the original associative memory can reappear after extinction training has led to a pervasive view that extinction involves the formation of new fragile, contextdependent learning that counteracts or inhibits the original learning (Rescorla and Cunningham, 1978; Robbins, 1990; Bouton, 1994).

However, recent research has indicated that, under certain conditions, extinction can "erase" the original associative memory, without reappearance of the original CR (Monfils et al., 2009;
Schiller et al., 2010). Apparent erasure has also been observed on the cellular level, where extinction training abolished the behavioral effects of associative fear conditioning and reversed conditioning-produced insertion of AMPA GluR1 receptors in mouse (Clem and Huganir, 2010) and rat (Mao et al., 2006) amygdala neurons. In Mao et al. (2006), extinction-produced cellular erasure effects were only observed when extinction was given shortly ( $1 \mathrm{~h}$, but not $24 \mathrm{~h}$ ) after the end of learning acquisition, suggesting that erasure might be sensitive to specific acquisitionextinction intervals.

Research in the invertebrate model system Hermissenda crassicornis (H.c.) has also demonstrated extinction-produced erasure of associative memories on both the behavioral and cellular levels (Richards et al., 1984; Cavallo et al., 2014). Associative memories in H.c. are formed using repeated pairings of light (CS) and high-speed rotation (US) (see Farley, 1988b; Crow, 2004; Blackwell and Farley, 2009 for review). Rotation stimulates the H.c. vestibular system (statocyst hair cells) and elicits a natural "clinging" response that inhibits locomotion toward 
light (phototaxis) (Lederhendler et al., 1986). Paired training using light and rotation produces marked suppression of phototactic behavior (CR), which was extinguished using repeated light-alone presentations without any evidence of spontaneous recovery (Richards et al., 1984; Cavallo et al., 2014) or reinstatement (using additional US presentations) (Cavallo et al., 2014) of the CR. Additional neurophysiological data supported the extinction-produced erasure hypothesis and found that extinction reversed conditioning-produced increases in Type B photoreceptor excitability, both in terms of the light response generator potential (Richards et al., 1984) and light-evoked spike frequencies (Cavallo et al., 2014). Because B cells are a principal site of memory storage (Farley and Alkon, 1980, 1982; Richards and Farley, 1987) that are causally related to suppressed phototaxis (Farley et al., 1983), this suggests that the extinction-produced reversal of conditioned behavior results from a corresponding attenuation of enhanced B cell excitability. The goal of the present research was to identify the molecular signaling pathways that mediate extinction-produced alterations in B cell excitability.

Associative conditioning (paired training) increases H.c. Type $\mathrm{B}$ cell excitability through reductions in somatic $\mathrm{K}^{+}$currents (Alkon et al., 1985; Farley, 1988a; Jin et al., 2009). These alterations are mediated, in part, by training-produced persistent activation of protein kinase C (PKC) (Farley and Auerbach, 1986; Farley and Schuman, 1991). Because PKC-mediated inhibition of $\mathrm{K}^{+}$channels underlies the increased excitability produced by associative conditioning, we hypothesized that extinction training would reverse this process by dephosphorylating $\mathrm{K}^{+}$channels (or channel-associated proteins) through the activation of protein phosphatase 1 (PP1). PP1 constrains learning-produced increases in Type B cell excitability in vitro (Huang and Farley, 2001) and has also been implicated as a principal molecule mediating extinction of conditioned taste aversion in mice (Stafstrom-Davis et al., 2001) and rats (Oberbeck et al., 2010). Protein phosphatase 2B (PP2B, aka calcineurin) is an upstream regulator of PP1 (Mulkey et al., 1994) that limits the expression of long-term memories in Aplysia (Sharma et al., 2003), constrains contextual fear learning in mice and mediates its extinction (Havekes et al., 2008). PP2B activity is also implicated in the extinction of fear potentiated startle responses in rats (Lin et al., 2003) and in extinction of conditioned taste aversion in mice (Baumgärtel et al., 2008). Therefore, we also examined whether the PP2B-PP1 signaling pathway participated in the extinction changes in $\mathrm{B}$ cell excitability. Additionally, because prior H.c. work has identified arachidonic acid (AA) and its metabolite 12(S)-hydroperoxyeicosatetraenoic acid [12(S)-HPETE] as molecules that reduce $\mathrm{B}$ cell excitability and enhance $\mathrm{K}^{+}$currents (Walker et al., 2010), we suspected that these molecules might also participate in extinction and decrease B cell excitability, as they do in the related phenomenon of conditioned inhibition (CI) learning (Walker et al., 2010).

To ascertain which molecular mechanisms mediate this process, we developed an in vitro protocol. Animals first received paired training (Paired), random presentations of light and rotation (Random), or no stimulation (Untrained). Next, B cells from isolated CNSs were recorded from during exposure to two series of 15 consecutive light-steps (LSs). When this extinction method was administered $2 \mathrm{~h}$ (but not $24 \mathrm{~h}$ ) after paired training, B cells from Paired animals showed large and progressive decreases in spike frequency by the 30th LS, while control cells did not. We then combined this protocol with pharmacological manipulations and found that several molecules involved in H.c. CI learning also contributed to the spiking decreases produced by in vitro extinction, including PP1, PP2B, and AA/12-LOX metabolites.

Finally, these data were incorporated into a conceptual framework to create a molecular model of extinction learning in H.c. (Figure 13). The key assumptions of this model are: (1) Paired conditioning increases $\mathrm{B}$ cell excitability through phosphorylation of somatic $\mathrm{K}^{+}$channels (or associated proteins), (2) In vitro extinction (repeated LSs) produces large increases in cytosolic $\mathrm{Ca}^{2+}$, but only in paired-trained cells, (3) Large intracellular $\mathrm{Ca}^{2+}$ levels preferentially activate PP2B, (4) PP2B disinhibits PP1, (5) PP1 dephosphorylates somatic $\mathrm{K}^{+}$channels (or associated proteins), which reduces $\mathrm{B}$ cell excitability, and (6) In vitro extinction further reduces $B$ cell excitability through the activation of a parallel AA/12-LOX pathway, which also interacts with somatic $\mathrm{K}^{+}$ channels.

\section{METHODS}

\section{ANIMALS}

Adult H.c. were provided by Monterey Abalone Co. (Monterey, CA) and individually housed in perforated $50-\mathrm{ml}$ plastic tubes in aquaria containing artificial seawater (ASW, Bio-sea Marine Mix, AquaCraft, Hayward, California, $\mathrm{pH} 7.8-8.2)$ at $15^{\circ} \mathrm{C}$ on a $6.5 / 17.5$-h light/dark cycle $\left(4 \mu \mathrm{W} / \mathrm{cm}^{2}\right.$ radiant intensity), as in Richards et al. (1984). Animals were fed with scallops (Mytilus edulis) twice weekly, but food was removed $48 \mathrm{~h}$ prior to behavioral testing.

\section{ANIMAL TRAINING}

The methods and apparatus used for behavioral training have been described previously (Farley, 1987a) and methods for extinction training were designed after Richards et al. (1984). Animals were placed into clear plastic tubes $(20 \mathrm{~cm})$ filled with ASW and mounted on a turntable in a refrigerator $\left(11^{\circ} \mathrm{C}\right)$. Vestibular stimulation consisted of high-speed rotation (100 RPM), resulting in a $2.24 \mathrm{~g}$ centrifugal force stimulation of the statocysts. Photoreceptors were stimulated using wholefield illumination provided by a $60 \mathrm{~W}$ incandescent light source $\left(56 \mu \mathrm{W} / \mathrm{cm}^{2}\right.$ intensity) located above the turntable. Timing and duration of stimuli were controlled automatically using an IBM DOS computer connected to digital/analog controllers made by department engineers. Animals were randomly assigned to one of three treatment conditions: Untrained, Paired, and Random. The Untrained animals received no behavioral training and remained in the home aquarium during scheduled training sessions. The Paired animals received two consecutive daily sessions of paired conditioning (50 trials each). One trial consisted of paired light and rotation (both $30 \mathrm{~s}$ ) presentations (simultaneous onsets and offsets), with an inter-trial interval (ITI) of 2 min (variable). Random animals received the same type of training as paired conditioning (same amount, stimulus duration, and ITI), but had stimuli presented randomly. 


\section{NERVOUS-SYSTEM PREPARATION AND INTRACELLULAR RECORDING}

General methods for preparing and performing electrophysiological recordings from H.c. nervous systems have been described extensively (e.g., Farley and Alkon, 1982, 1987; Farley, 1987a,b, 1988a). Dissected H.c. circumesophageal nervous systems (Figure 1) were secured on a microscope slide within a $495 \mu \mathrm{L}$ well of ASW $\left(15^{\circ} \mathrm{C}\right)$. Each isolated nervous system was incubated in protease $(1 \mathrm{mg} / \mathrm{ml}$; Subtilisin A, Sigma P5380) for $\sim 8-9 \mathrm{~min}$ at room temperature $\left(\sim 18-20^{\circ} \mathrm{C}\right)$ to facilitate cell impalement. After protease exposure, nervous systems were rinsed with ten volumes of cold $\left(4^{\circ} \mathrm{C}\right)$ standard ASW.

\section{IN VITRO EXTINCTION PROTOCOL}

Methods for in vitro conditioning using isolated H.c. nervous systems have been previously developed for simulating paired conditioning (Farley, 1987b; Farley and Alkon, 1987; Grover and Farley, 1987; Huang and Farley, 2001; Jin et al., 2009). Based on these studies, we developed an in vitro extinction protocol that delivered two sets of 15 LSs to isolated H.c. CNSs from conditioned or Untrained animals. Animals were dissected and standard electrophysiological experiments were performed on Type B photoreceptors (Farley and Alkon, 1982; Farley, 1987b, 1988a). B cells from Random animals were recorded from $\sim 1-2 \mathrm{~h}$ after training concluded, while Paired cells were recorded from $\sim 1-2 \mathrm{~h}$ or $24 \mathrm{~h}$ after associative conditioning. B cells were impaled and dark-adapted for $15 \mathrm{~min}$, while continuously monitoring spontaneous spiking and synaptic activity. Following dark adaptation, cells were exposed to 15 presentations of a $30 \mathrm{~s}$ LS ( 2 min ISI). These 15 LSs were designed as a replacement for whole-animal extinction training (Richards et al., 1984), which comprises 25 light-alone presentations following paired conditioning. Thus, our in vitro extinction method entailed repeated sequential $30 \mathrm{~s}$ LS presentations of the same intensity, duration, and frequency as those used during extinction training given to intact animals. After the first 15 LSs, cells were re-dark adapted for $10 \mathrm{~min}$, and given another 15 LSs. The intervening dark adaptation period

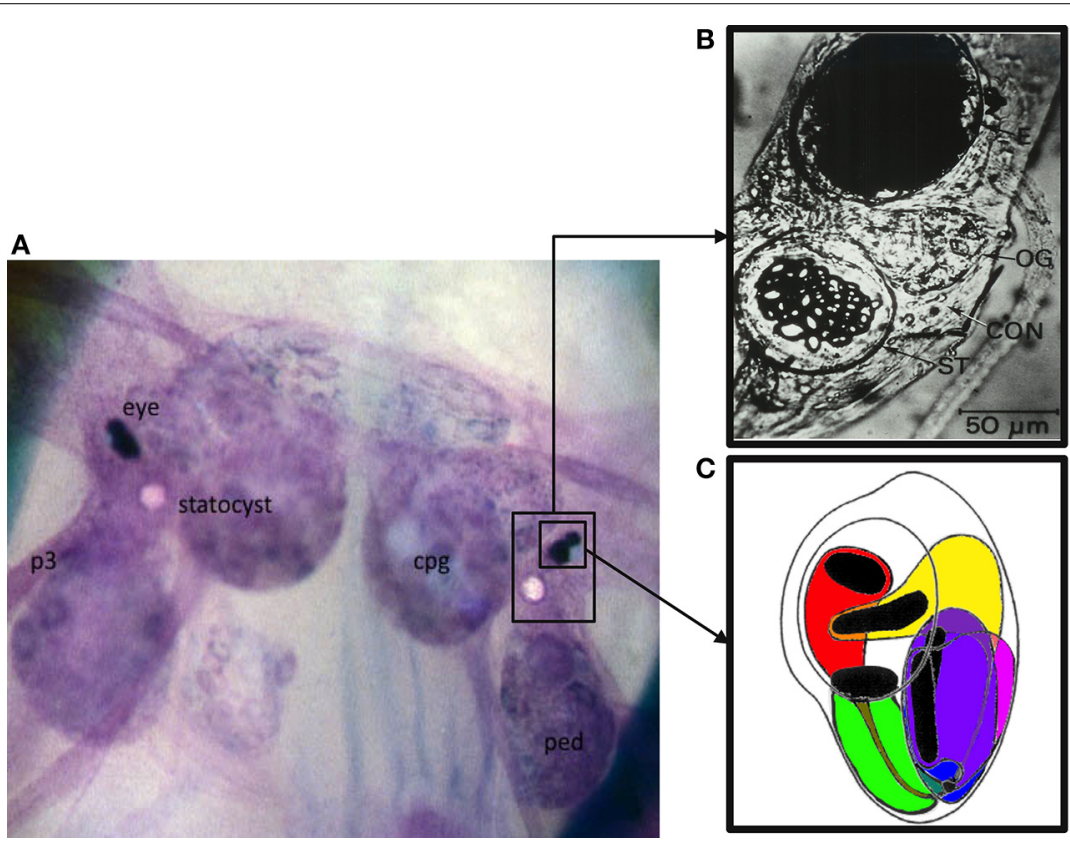

FIGURE 1 | The Hermissenda (H.c.) circumesophageal nervous system (CNS): entire CNS, eye, and statocyst. (A) Low resolution macrophotograph of an in situ toluidine-blue stained CNS. Note that the eye and statocyst lie on the dorsal surface of the CNS, in between the cerebropleural (cpg) and pedal (ped) ganglia. Pedal nerves (e.g., p3) project from the pedal ganglia down to the pedal musculature. (B) Photomicrograph of a H.c. eye (top, dark structure) and statocyst (bottom, ST, crystalline structure). Non-excitable, and non-photoresponsive pigmented cells are responsible for the black appearance of the eye, and obscure the photoreceptors. Portions of the photoreceptors are visible along the bottom of the eye. (C) Schematic drawing of a right eye, illustrating the relative positions of the three Type B photoreceptors (medial, intermediate, and lateral, colored here as green, purple, and magenta, respectively) and the two Type A photoreceptors (medial and lateral, colored here as red and yellow, respectively). Note the black rhabdomeric portions of the photoreceptors, where phototransduction occurs. The rhabdomeres are oriented toward the lens. Note also that each photoreceptor has an axo-dendritic process extending from its base. The one extending from the (red) medial A photoreceptor is shown here in gray, running over the soma of the medial Type B photoreceptor. The axo-dendritic processes collect and fasciculate at the base of the eye, to form the optic nerve, which projects underneath the optic ganglion (see B) into the cerebropleural ganglia, where it extensively ramifies. Action potentials are generated at the axon hillock region. The majority of fast synaptic potentials (EPSPs and IPSPS) originate distal to the axon hillock at the axo-dendritic ramifications. A variety of slow synaptic responses (e.g., originating from GABA B, muscarinic Ach, and 5-HT GPCRs) are located on the axo-dendritic process and soma. The soma is non-spiking. An appropriately located razor lesion of the axon (optic nerve), close to the base of the eye, eliminates action potentials and fast synaptic potentials, without affecting the light-induced generator potentials, light adaptation, or slow synaptic responses from exogenously applied neurotransmitters. In the synaptically-intact preparation, action potentials recorded from the soma propagate passively and in a retrograde fashion from the axon hillock. Sharp electrode intracellular recordings (and two microelectrode voltage clamp) from the soma allow one to readily record light-induced generator potentials, superimposed action potentials, and synaptic potentials (fast and slow). 
was administered to minimize light-adaptation effects on B cell excitability that might have accumulated as a result of the first 15 LSs (Farley, 1987a). Light adaptation in invertebrate photoreceptors is a molecular desensitization process that is mechanistically distinct from extinction (Lisman and Brown, 1972; Bader et al., 1976).

\section{PHOSPHATASE ENZYMES AND INHIBITORS}

Activity of catalytically active protein phosphatase 1 (caPP1) $(\alpha$-isoform, derived from rabbit skeletal muscle, produced via recombinant E. coli, Calbiochem, cat. No. 539493) was 2500 units/mL and was dissolved in buffer to obtain 500 activity units/mL. caPP1 buffer was composed of (in mM): 50 HEPES, $200 \mathrm{NaCl}, 1 \mathrm{MnCl}_{2}, 0.1$ EGTA, 2.5 DTT, 0.025\% Tween 20 (Polyoxyethylenesorbitan Monolaurate, Sigma P-1379), and $50 \%$ glycerol. caPP1 was further diluted in buffer $(661.7 \mathrm{nM}$ final concentration), backfilled into microelectrodes, and filled with $1.5 \mathrm{M} \mathrm{KCl}$. caPP1 was introduced into a single B cell via leakage/ionophoresis through the recording electrode using five, $30 \mathrm{~s}-0.5 \mathrm{nA}$ current injections during the first dark adaptation period.

Catalytically active protein phosphatase $2 \mathrm{~B}$ (caPP2B) was obtained as a gift from Dr. Claude Klee. Recombinant caPP2B (rCnAB45) $(14 \mu \mathrm{g} / \mathrm{ml}$ concentration) was suspended in buffer (in $\mathrm{mM}$ ): 40 Tris, $100 \mathrm{GuHCl}, 100 \mathrm{NaCl}, 0.1 \mathrm{CaCl}_{2}, 2$ DTT, and $100 \mu \mathrm{g} / \mathrm{ml}$ soybean inhibitor. caPP2B activity was $15-20 \mathrm{nmol} / \mathrm{min}$, in the assay with $1 \mathrm{nM} \mathrm{rCnAB} 45$, in a buffer of (in mM): 40 Tris, $100 \mathrm{NaCl}, 0.4 \mathrm{mg} / \mathrm{ml} \mathrm{BSA}, 0.6 \mathrm{CaCl}_{2}, 0.5 \mathrm{MnCl}_{2}$, and 1 DTT. caPP2B was backfilled into electrodes, filled with 1.5 $\mathrm{M} \mathrm{KCl}$, and introduced into B cells using the same methods described for caPP1.

Calyculin A (Sigma-Aldrich \#C5552) was dissolved in dimethylsulfoxide (DMSO) ( $0.1 \mathrm{mM}$ concentration), then diluted with $\mathrm{dH}_{2} \mathrm{O}$ to a stock concentration of $2 \mu \mathrm{M}$. Five microliter of stock solution was added to the ASW bath $(20 \mathrm{nM}$ final concentration). Cyclosporin A (Sigma-Aldrich \#C3662) was dissolved in $3 \mathrm{M} \mathrm{KCl}(0.01 \%$ DMSO) ( $100 \mathrm{nM}$ final concentration). Concentrations of calyculin and cyclosporin were 10-20 higher than $\mathrm{IC}_{50}$ values reported for inhibition of PP1 (Resjö et al., 1999) and PP2B (Fruman et al., 1992), and identical to concentrations used in prior H.c. research (Huang and Farley, 2001).

\section{ARACHIDONIC ACID AND METABOLITE INHIBITORS}

AA (Sigma-Aldrich \#A8798) was stored at a stock concentration of $0.1 \mathrm{M}$ in $100 \%$ ethanol at $-70^{\circ} \mathrm{C}$. Daily AA solutions were prepared by diluting stock solutions to $10 \mathrm{mM}$ with $\mathrm{dH}_{2} \mathrm{O}$. Baicalein (Sigma \#465119) was stored in powder form at $4^{\circ} \mathrm{C}$ and $10 \mathrm{mM}$ solutions were prepared daily in $\mathrm{dH}_{2} \mathrm{O}$. Final bath concentrations of $\mathrm{AA}$ and baicalein were $100 \mu \mathrm{M}$, and ethanol concentrations never exceeded $0.1 \%$.

\section{DATA AND STATISTICAL ANALYSIS}

Several measures of $B$ cell excitability were obtained, including: resting membrane potential $\left(\mathrm{V}_{\mathrm{m}}\right)$, input resistance $\left(\mathrm{R}_{\mathrm{in}}\right)$, and light-evoked spike frequency (number of action potentials, in $\mathrm{Hz}$, during the last $10 \mathrm{~s}$ of LS). Input resistance was calculated using Ohms law. Brief ( $200 \mathrm{~ms}$ ) current pulses of $-0.25 \mathrm{nA}$ were given and voltage drops were recorded. $B$ cells with a $V_{m}$ more positive than $-39 \mathrm{mV}$ and a $R_{i n}$ of less than $30 \mathrm{M} \Omega$ were considered damaged and were discarded.

Differences in B cell spike frequency during LSs 1-2 (averaged) were determined using One-Way ANOVA and Bonferroni post-hoc tests. Analysis of LSs 6-30 and LSs 16-30 were done using repeated measures ANOVA comparisons and Bonferroni post-hoc pairwise tests. All statistics were performed using the SPSS 20.0 software suite. In cases where a Mauchly's test of sphericity revealed a violation of sphericity $(p<0.05)$, a GreenhouseGeisser correction was used. Two-tailed significance tests were used (unless otherwise noted), and significant $p$-values are $<0.05$.

\section{RESULTS}

Learning-produced alterations in phototactic behavior are correlated with increased light-evoked frequencies in Type B cells (Farley and Alkon, 1982) that drive downstream changes in sensory-interneuron-motoneuron circuits that control locomotor behavior (Goh et al., 1985; Richards and Farley, 1987; Crow, 2004). Behavioral extinction training of intact animals using short acquisition-extinction intervals $(15 \mathrm{~min})$ appeared to reverse this cellular correlate of paired conditioning and abolished the learning-produced increases in B cell light-evoked spike frequencies when measured $24 \mathrm{~h}$ after conditioning (Cavallo et al., 2014). To investigate the cellular changes that occur during extinction training in real-time, we developed an in vitro extinction protocol. Isolated CNSs from associatively trained (Paired), or control animals (Untrained and Random) were exposed to two sets of 15 successive light presentations (light steps, LSs), commencing $\sim 2 \mathrm{~h}$ after the conclusion of conditioning. Light-evoked spike activity of Type B photoreceptors was tabulated during each LS. LSs were the same duration ( $30 \mathrm{~s}$ ), frequency ( $2 \mathrm{~min}$ ISI), and intensity as LSs given to intact animals during behavioral extinction experiments. Associative conditioning can be simulated in semi-intact preparations or in isolated CNSs using several procedures [e.g., light-B cell depolarization (Farley et al., 1983), light-statocyst hair cell stimulation (Farley and Alkon, 1982, 1987; Farley, 1987b; Grover and Farley, 1987)]. Because these methods produce many of the same learning-produced alterations in B cell excitability and phototactic behavior elicited by paired training in vivo, the current procedure consisting of LSs presented to isolated CNSs was used to act as a substitute for whole-animal extinction training (e.g., Richards et al., 1984). We then combined this in vitro extinction protocol with selective pharmacological inhibition of the PP1/PP2B phosphataseand AA/12(S)-HPETE fatty acid-signaling pathways, injection of purified constitutively-active phosphatases, and stimulation with AA. Our results indicated that both phosphatase- and lipidsignaling pathways appeared to be involved in the reductions in $\mathrm{B}$ cell excitability produced by in vitro extinction.

\section{IN VITRO EXTINCTION PRODUCES A PROGRESSIVE DECREASE IN B CELL SPIKE FREOUENCY, BUT ONLY IN PAIRED-CONDITIONED CELLS}

As reported in Cavallo et al. (2014, Figure 7) and summarized again here in Figures 2A,B, Type B cells from Paired $(n=11)$ animals exhibited greater light-evoked spike frequencies during LSs $1-2(7.44 \pm 0.31 \mathrm{~Hz})$ than cells from control animals (Random, 

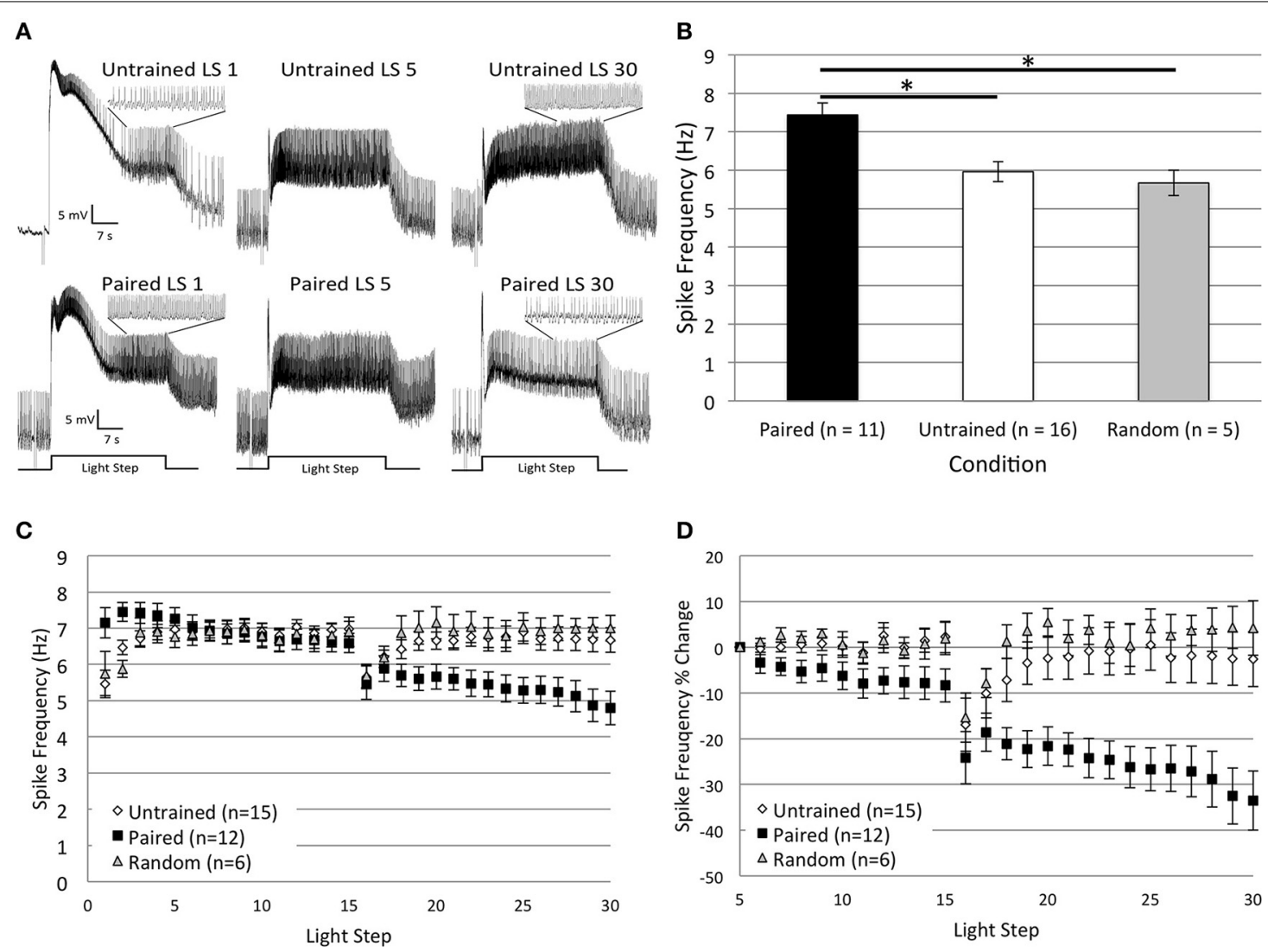

FIGURE 2 | Thirty repeated light presentations (extinction training) produced a progressive reduction in Type B cell spike frequency, but only in paired-trained cells. (A) Representative light responses recorded from either untrained (top traces) or paired-trained (bottom traces) Type B photoreceptors from isolated H.c. nervous systems. Recordings from Paired animals were obtained $2 \mathrm{~h}$ following the conclusion of paired conditioning. Light-evoked spike frequencies were recorded during two consecutive sets of 15 repeated light steps (LSs), 2 min inter-stimulus intervals, separated by a $10 \mathrm{~min}$ re-dark adaptation period. This procedure served as an in vitro simulation of whole-animal extinction training. Spike frequencies were recorded over the last $10 \mathrm{~s}$ of each $30 \mathrm{~s}$ LS. Inset traces above LSs 1 and 30 for both Paired and Untrained cells show expanded time scale during last $10 \mathrm{~s}$ of LS. Note the more frequent spiking activity in the Paired cell during LS 1 compared to the Untrained cell, indicative of excitability increases due to associative learning. Both cells had approximately equivalent spike frequencies by LS 5 , but after this, the Paired cell exhibited a progressive reduction in spike frequency over the course of the next 25 LSs. By LS 30, the Paired cell spiked less frequently than the

Untrained control cell. (B) Summary spike frequency data for paired-trained cells and control cells during LSs 1-2 (reported in Cavallo et al., 2014). Paired conditioning increased Type B cell spike frequency during LSs 1-2 above Untrained and Random (non-associative) control cells, which did not differ. (C) Summary spike frequency data for two sets of 15 consecutive LSs. Paired cells showed a progressive reduction in spike frequency and exhibited significantly lower spike frequencies during LSs 16-30 compared to Untrained and Random control cells. (D) Summary spike frequency data of the percent change in spike frequency relative to the 5th LS. Paired cells showed a steady and significant decrease in spike frequency over the course of 30 repetitive LSs compared to Untrained and Random cells, which showed very little change. Error bars are \pm s.e.m. and significant $p$-values ( $p$ 's $<0.05$ ) are denoted by an asterisk. Note that the sample size for the Untrained $(n=15)$ group was different than what was reported for LSs 1-2 $(n=16)$ because impalement of one cell was lost after LS 24. One Paired and one Random cell were excluded from LSs 1-2 analysis because electrical noise prevented unambiguous determination of spike frequencies during this period.

$n=5,5.67 \pm 0.33 \mathrm{~Hz}$; Untrained, $n=16,5.96 \pm 0.26 \mathrm{~Hz}) 2 \mathrm{~h}$ after the end of associative conditioning. This increased excitability was followed by a large and progressive decline in spiking during later LSs that was unique to Paired cells and did not occur in control cells (Figures 2A,C). The initial differences in spike frequencies between Paired and control groups diminished with successive LSs (Figure 2C), as observed previously (Farley, 1987a). Spike frequencies were similar for the Paired and control groups throughout LSs 4-15. After a re-dark adaptation period (10 min), spike frequencies of these groups began to diverge with successive LSs. Paired cells showed a steady decline in spiking during LSs
16-30. A repeated measures ANOVA compared the three groups over LSs $16-30$ and revealed that Paired $(n=12)$ cells spiked significantly less frequently than Untrained $(n=15)\left[F_{(1,25)}=\right.$ 7.26, $p=0.012]$, and Random $\left[F_{(1,16)}=6.73, p=0.02\right]$ cells (Figure 2C), while control cells failed to differ $\left[F_{(1,19)}=0.20\right.$, $p=0.659]$.

Because cells from Paired animals initially spiked at higher rates than controls, the decreases in spike frequencies might be more conspicuous for Paired cells because of the greater room for decline. Therefore, we also analyzed the relative changes in spike frequency by calculating a percent change score for each 
cell. The spike frequency of a cell during each LS 6-30 was compared to the spiking during LS 5 for that same cell, when spike frequencies had stabilized and initial training-associated differences were on average no longer apparent. This analysis yielded qualitatively similar results to those reported for absolute spike frequencies. Around LS 6-7, Paired cells began to show a progressive decrease in spike frequency that was not evident in control cells (Figure 2D). By the 30th LS, cells from the Paired group showed a $33.5 \pm 6.5 \%$ decrease in spike frequency, which was much larger than the small changes evident in Untrained $(2.6 \pm 6.0 \%$ decrease $)$ and Random $(4.2 \pm 7.7 \%$ increase $)$ control cells. A repeated measures ANOVA compared the three conditions across LSs 6-30 and revealed that the spike frequency decrease in Paired cells was significantly larger than in Untrained $\left[F_{(1,25)}=\right.$ $10.06, p=0.004]$ and Random cells $\left[F_{(1,16)}=15.08, p=0.001\right]$. Untrained and Random control cells failed to differ $\left[F_{(1,19)}=\right.$ $0.26, p=0.618$ ] (Figure 2D). These results indicate that repetitive LSs produced a reduction in B cell spike frequency that was contingent upon prior associative conditioning. These findings paralleled the behavioral in vivo extinction results (Figure 7B from Cavallo et al., 2014) and suggest that 30 successive LSs given to isolated H.c. CNSs was an effective in vitro extinction protocol for producing extinction-correlated reductions in $\mathrm{B}$ cell excitability.

\section{OMISSION OF THE DARK ADAPTATION PERIOD BETWEEN LSS 15 AND 16 DOES NOT AFFECT IN VITRO EXTINCTION}

The previous in vitro extinction experiments included a $10 \mathrm{~min}$ re-dark adaptation period between the two sets of 15 LSs to ensure that any changes in B cell excitability produced by in vitro extinction resulted from the extinction process rather than from changes due to light adaptation (see Methods). The question arises as to whether the emergence of the spike frequency differences during LSs 16-30 for Paired vs. control cells was predominantly due to: (1) the additional $10 \mathrm{~min}$ per se, (2) the additional dark adaptation that occurred, (3) the additional LSs, or (4) some combination/interaction of these factors. To address this question, we repeated the in vitro extinction experiments for different groups of Paired and Untrained cells, but omitted the intervening re-dark adaptation period. Thus, cells in each group (Paired no dark adaptation, NDA, and Untrained NDA) were given 30 consecutive LSs with the same LS interval, duration, and intensity used in the prior experiments, but without additional dark adaptation between LSs 15 and 16. Even without the re-dark adaptation period, the same general pattern emerged. Thirty successive LSs produced a progressive reduction in spike frequencies in Paired, but not in Untrained cells (Figure 3).

Paired NDA cells $(n=6)$ showed significantly greater levels of light-evoked spike frequencies than Untrained NDA $(n=5)$ cells during LSs $1-2(8.45 \pm 0.27 \mathrm{~Hz}$ vs. $7.38 \pm 0.34 \mathrm{~Hz}$, respectively) $\left[t_{(1,9)}=2.48, p=0.035\right]$. During later LSs 16-30, a repeated measures ANOVA found that Paired NDA cells $(n=5)$ exhibited a progressive and significant decrease in spike frequency with successive LSs when compared to Untrained NDA cells (Figure 3A) [significant interaction between LS and condition: $F_{(14,112)}=$ 4.97, $p=0.000$ ]. This indicated that repeated LSs produced a reduction in spike frequency, but only in Paired cells.

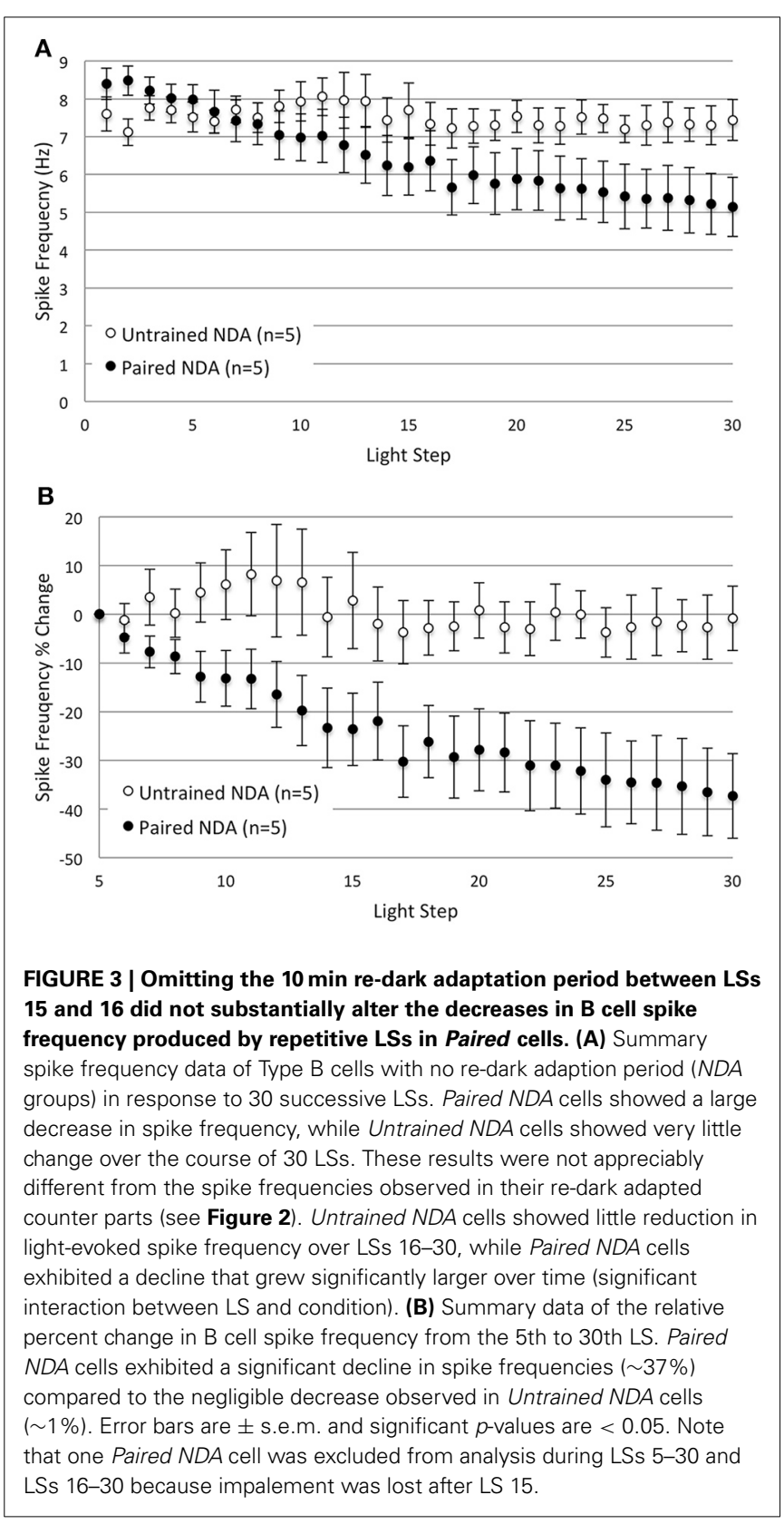

We next compared Untrained NDA and Paired NDA groups with their re-dark adapted counterparts and found that they generally did not differ. Spike frequencies of Untrained NDA cells during LSs 16-30 did not significantly differ from Untrained re-dark adapted cells (Untrained group from previous experiment) $\left[F_{(1,18)}=1.72, p=0.206\right]$. Although a significant interaction between LS and condition was found $\left[F_{(2.93,52.79)}=2.91\right.$, $p=0.044$, corrected for sphericity], pairwise comparisons of each LS indicated that Untrained NDA cells spiked more frequently than Untrained re-dark adapted cells, but only at LS $16(p=0.023)$. This transient difference in spike frequency was a result of the $10 \mathrm{~min}$ dark adaptation period and was gone by LS 17 (see Figure 2C). No other differences were detected during LSs 17-30. Spike frequencies of Paired NDA and Paired 
re-dark adapted cells did not differ significantly $\left[F_{(1,15)}=0.07\right.$, $p=0.790]$.

The same pattern and conclusions were obtained when spike frequencies were analyzed as a percent change from the 5 th to 30th LS (Figure 3B). Paired NDA cells showed a large $37.3 \pm$ $8.7 \%$ reduction in spike frequency by the 30 th LS that was significantly greater than Untrained NDA cells $(0.9 \pm 6.6 \%$ decrease $)$ [main effect of treatment condition, $F_{(1,8)}=6.86, p=0.031$ ] (Figure 3B). Spike frequencies of Untrained NDA and Paired NDA groups were no different from their re-dark adapted counterparts $\left[F_{(1,18)}=0.10, p=0.761\right.$, and $F_{(1,15)}=1.06, p=0.320$, respectively]. These data confirmed that in vitro extinction led to a progressive reduction in Paired B cell spike frequency that took time and repetitive LSs to develop, regardless of the middle re-dark adaptation period.

\section{CALYCULIN A PARTIALLY BLOCKS THE EFFECTS OF IN VITRO EXTINCTION}

Prior research found that inhibition of PP1 mimicked and occluded further increases in Type B cell excitability produced by in vitro paired conditioning, suggesting that PP1 might limit $B$ cell excitability and oppose the pairing-produced effects of PKC activation (Huang and Farley, 2001). Because inhibitory conditioning (Britton and Farley, 1999) and extinction training produce directionally similar behavioral and electrophysiological effects (enhanced phototaxis, reduced B cell excitability), we hypothesized that PP1 activity might also be recruited during in vitro extinction. To test this, we exposed $\mathrm{B}$ cells to the PP1 inhibitor, calyculin $\mathrm{A}$, for $15 \mathrm{~min}$ prior to in vitro extinction training. We predicted that inhibition of PP1 during the course of in vitro extinction would block the progressive decrease in spike frequency observed in Paired cells, but have little effect in control cells. Consistent with this expectation, Paired cells incubated in calyculin showed a much smaller reduction in spike frequency compared to their Paired (no drug) counterparts (Figure 4).

Incubation in calyculin did not affect the average spike frequencies of Paired (Paired + Calyculin, $n=8,6.34 \pm 0.47 \mathrm{~Hz}$ ) or Untrained (Untrained + Calyculin, $n=7,5.79 \pm 0.69 \mathrm{~Hz}$ ) cells during LSs 1-2 compared to their no drug counterparts. At later LSs 16-30, Paired + Calyculin cells $(n=7)$ showed
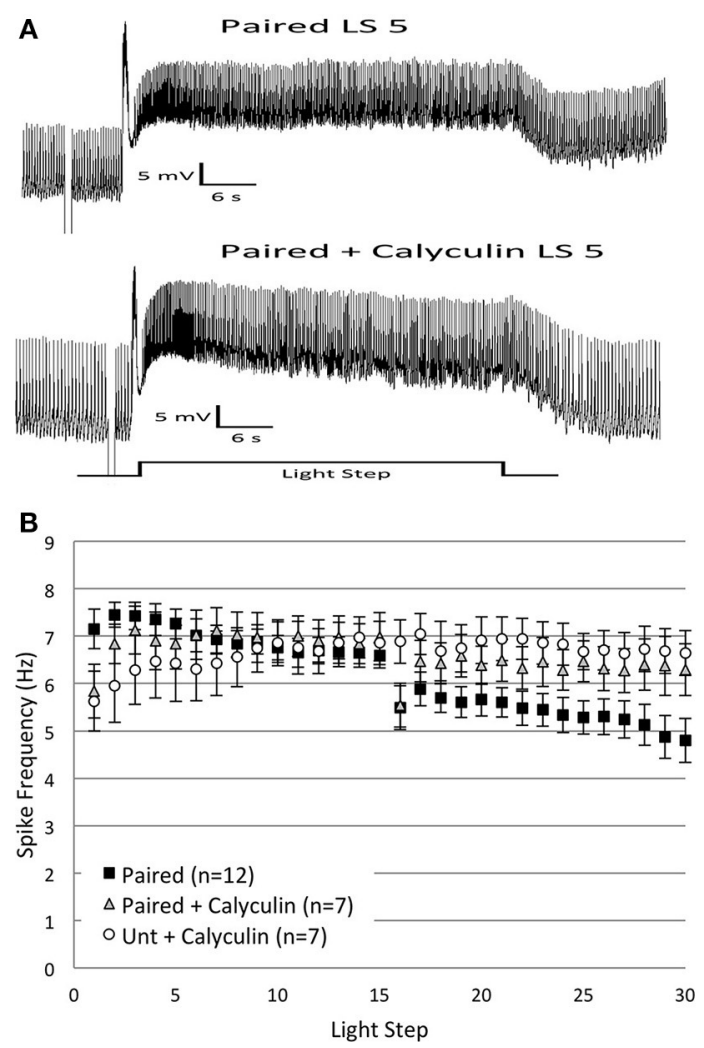

FIGURE 4 | Bath application of calyculin A (20 nM), an inhibitor of PP1, blocked the reductions in spike frequency produced by repeated LSs in Paired cells, when measured as a percent change in spike frequency. (A) Representative light responses recorded from a Paired Type B cell (top trace) or a Paired cell incubated in calyculin A (Paired + Calyculin; bottom trace) for $15 \mathrm{~min}$ prior to in vitro extinction. The Paired cell showed a significant decline in light-evoked spike frequency $(40 \%)$ from the 5 th to 30th LS, while the Paired + Calyculin cell showed a $21 \%$ increase. (B) Summary spike frequency data of Type B cells exposed to calyculin A. The large reduction in spike frequency observed in Paired (no drug) cells during LSs 16-30 was qualitatively smaller when Paired cells were incubated in
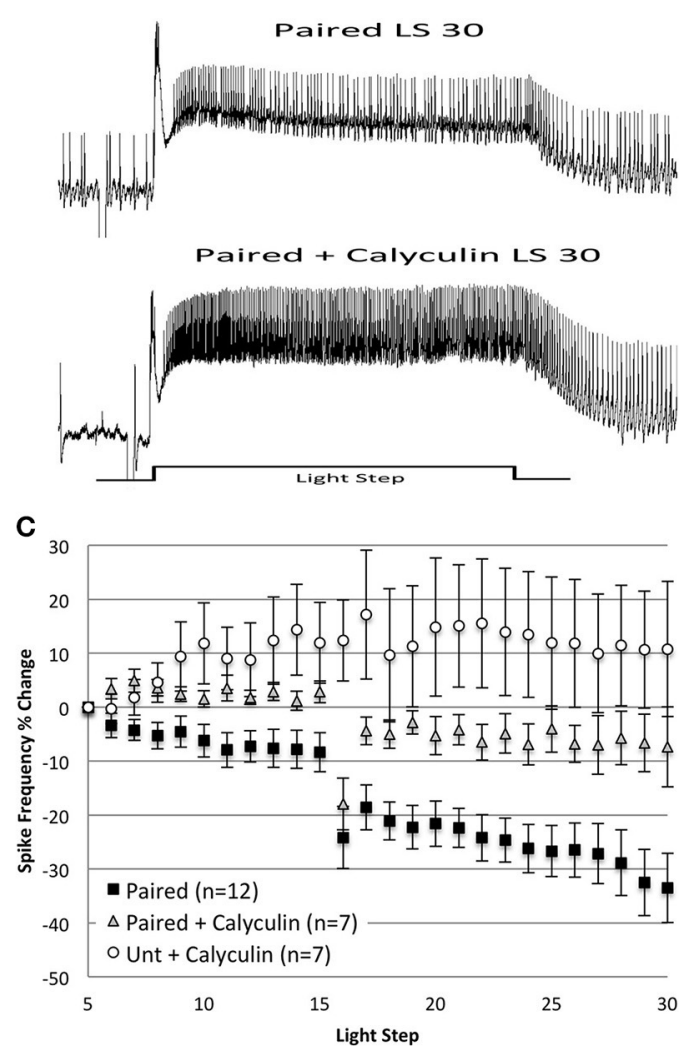

calyculin and was no different than the spike frequencies of Untrained cells incubated in calyculin (Unt + Calyculin). (C) Summary data of the relative percent change in $B$ cell spike frequency from the 5th to 30th LS. The incubation of Paired cells in calyculin significantly attenuated the large decrease in spike frequency over the course of 30 LSs normally exhibited by Paired cells without drug. Paired + Calyculin cells spiked at frequencies not statistically different from Unt + Calyculin cells, but frequencies significantly greater than Paired (no drug) cells. Error bars are \pm s.e.m. and significant $p$-values are $<0.05$. Note that one cell in the Paired + Calyculin group was omitted from spike frequency analysis during LSs 5-30 and LSs 16-30 because impalement was lost after LS 25. 
a small reduction in spike frequencies that was not different from Untrained + Calyculin cells $\left[F_{(1,12)}=0.52, p=\right.$ $0.485]$, nor from Untrained (no drug) cells $\left[F_{(1,20)}=0.25, p=\right.$ 0.624] (Figures 4A,B), indicating that calyculin blocked the large decrease in spike frequency and maintained spike frequencies at control levels. Paired + Calyculin cells exhibited spike frequencies that were not significantly greater than Paired (no drug) cells during this period $\left[F_{(1,17)}=2.73, p=0.117\right]$.

The effects of calyculin were more apparent when analyzed as a percent change in spike frequency from the 5th to 30th LS (Figure 4C). Paired + Calyculin cells showed a negligible $5.6 \pm$ $7.4 \%$ decrease in spike frequency over the course of 30 LSs that was not different from Untrained + Calyculin cells $(10.8 \pm$ $12.5 \%$ increase) $\left[F_{(1,12)}=2.21, p=0.163\right]$ (Figure 4C), nor from Untrained (no drug) cells $\left(2.6 \pm 6.0 \%\right.$ decrease) $\left[F_{(1,20)}=\right.$ $0.02, p=0.893]$. In contrast, the $5.6 \pm 7.4 \%$ decrease in spike frequency observed in Paired + Calyculin cells was significantly different from Paired (no drug) cells (33.5 $\pm 6.5 \%$ decrease) $\left[F_{(1,17)}=11.08, p=0.004\right]$ (Figure 4C). Thus, pre-incubation of B cells in calyculin prevented the large spike frequency decrease produced by in vitro extinction in Paired cells.

\section{PROTEIN PHOSPHATASE 1 OCCLUDES FURTHER SPIKE FREQUENCY REDUCTIONS IN PAIRED CELLS AND PARTIALLY MIMICS THE EFFECTS OF IN VITRO EXTINCTION IN UNTRAINED CELLS}

To further investigate the involvement of PP1 in the in vitro extinction process, we injected the catalytically active subunit of PP1 (caPP1) into B cells prior to the administration of 30 LSs. If in vitro extinction activates endogenous $\mathrm{PP} 1$, and thereby contributes to the progressive decrease in B cell spike frequencies, then injection of exogenous caPP1 into Paired cells should also reduce spike frequencies and occlude any further reductions that result from repetitive LSs (i.e., in vitro extinction). Injections of caPP1 into Untrained cells might also reduce spike frequencies due to dephosphorylation of spike-regulating $\mathrm{K}^{+}$channels. These reductions might not be apparent immediately, but could develop over time, owing to delays associated with intracellular enzyme diffusion, dephosphorylation rates, etc.

In support of the PP1-involvement hypothesis, Untrained and Paired cells injected with caPP1 exhibited reductions in spike frequency during later LSs 16-30, (Figures 5A,C), an effect more pronounced when measured as a percent change in spike frequency (Figure 5D). The reduction in spike frequency seen in Paired cells injected with caPP1 was not greater than what was observed in Paired (no drug) cells. Thus, caPP1 injection appeared to partially mimic and occlude the effects of in vitro extinction on B cell spike frequency.

An ANOVA of LSs 1-2 compared the average spike frequency of Untrained and Paired cells with their caPP1-injected counterparts and the Buffer control group, and found a main effect of treatment condition $\left[F_{(4,47)}=4.63, p=0.003\right]$. Post-hoc analysis revealed that injection of caPP1 into Untrained cells (Untrained $+P P 1 ; n=11)$ significantly increased spike frequencies compared to Untrained (no drug) cells $(7.60 \pm 0.29 \mathrm{~Hz}$ vs. 5.96 $\pm 0.26 \mathrm{~Hz}$, respectively) $(p=0.005)$, but not compared to PP1 Buffer controls $(n=7)(6.74 \pm 0.64 \mathrm{~Hz})(p=1.0)$. This indicated that the increased spike frequencies observed in Untrained + PP1 cells were partly due to non-specific effects of the PP1 buffer. Paired + PP1 cells $(n=7)$ were no different than Paired (no drug) cells during LSs $1-2(7.19 \pm 0.39 \mathrm{~Hz}$ vs. $7.44 \pm 0.31 \mathrm{~Hz}$, respectively) ( $p=1.0)$.

Spike frequencies of Untrained + PP1 and Paired + PP1 cells remained approximately at control levels from LSs 4-15 (Figure 5C). During LSs 16-30, Untrained + PP1 cells showed slight (non-significant) decreases in spike frequencies below Untrained $\left[F_{(1,24)}=0.05, p=0.829\right]$ and Buffer control $\left[F_{(1,16)}=2.44, p=0.138\right]$ levels, and were significantly higher than Paired (no drug) cells $\left[F_{(1,21)}=6.74, p=0.017\right]$ (Figure 5C). Buffer control cells showed slight (non-significant) increases in spike frequencies compared to Untrained cells $\left[F_{(1,20)}=3.70, p=0.069\right]$ (Figure 5B). This suggests that the small excitatory effects of the PP1 buffer opposed reductions in spike frequencies produced by caPP1 injection, and thereby prevented caPP1 from reducing spike frequencies below Buffer or Untrained control levels.

Paired + PP1 cells showed progressive declines in spike frequencies during LSs 16-30 that were no different than the decreases observed in Paired (no drug) cells $\left[F_{(1,17)}=0.61\right.$, $p=0.446]$, and were significantly below Buffer $\left[F_{(1,12)}=13.90\right.$, $p=0.003]$, but not Untrained $\left[F_{(1,20)}=2.48, p=0.131\right]$ cells (Figure 5C). Thus, caPP1 injection into Paired cells produced decreases in spike frequencies that were not larger than the decreases observed in Paired (no drug) cells, and appeared to occlude the effects of repeated LSs and any further reductions in spike frequency.

To further evaluate the effects of caPP1 injections, we analyzed the relative changes in spike frequencies, measured as a percent change from the 5 th to 30 th $\mathrm{LS}$. Untrained $+P P 1$ cells showed a $20.0 \pm 3.1 \%$ reduction in spike frequency by the 30th LS that was nominally less, but not significantly different, than Paired (no drug) cells $(33.5 \pm 6.5 \%$ reduction) $\left[F_{(1,21)}=2.77, p=0.111\right]$ (Figure 5D). This decreased spike frequency of Untrained + PP1 cells was significantly greater than Buffer control cells $(1.1 \pm 3.0 \%$ decrease $)\left[F_{(1,16)}=\right.$ $11.34, p=0.004]$, and qualitatively greater than Untrained control cells $(2.6 \pm 6.0 \%$ decrease $)\left[F_{(1,24)}=3.97, p=0.058\right]$. Paired + PP1 cells showed a significant $21.6 \pm 2.4 \%$ reduction in spike frequency from the 5 th to 30th LS compared to Buffer $\left[F_{(1,12)}=21.55, p=0.001\right]$ and Untrained $\left[F_{(1,20)}=\right.$ $5.11, p=0.035]$ control cells, that occluded any further decreases produced by in vitro extinction, and was not significantly different than Paired (no drug) cells $\left[F_{(1,17)}=0.57, p=0.462\right]$ (Figure 5D).

In summary, Untrained cells injected with caPP1 showed spike frequency reductions that mimicked those observed in Paired cells (without caPP1) during in vitro extinction. The declines in spike frequencies due to in vitro extinction in Paired cells injected with caPP1 were no greater than those observed in Paired cells (without caPP1), suggesting that caPP1 occluded the spike frequency reductions produced by repeated LSs during in vitro extinction. Combined with the calyculin data reported above, these results are consistent with the hypothesis that endogenous $\mathrm{PP} 1$ is involved in the in vitro extinction-produced changes in $\mathrm{B}$ cell excitability. 

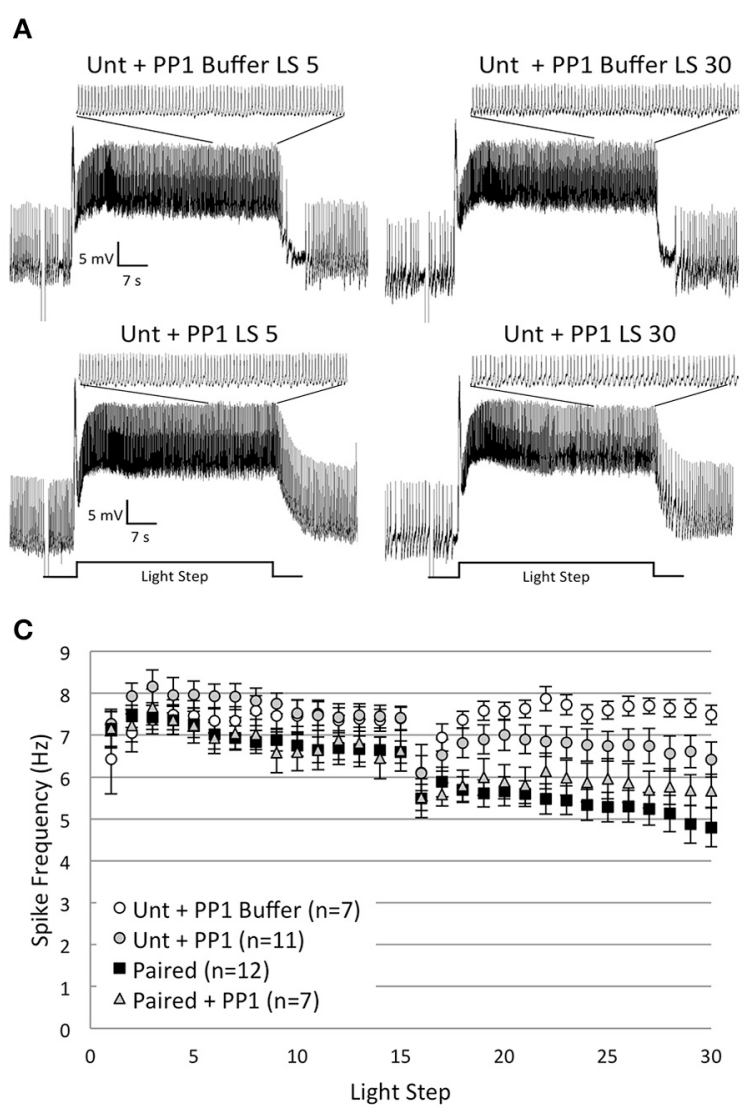

FIGURE 5 | Injection of catalytically active protein phosphatase 1 (caPP1) reduced spike frequencies in Untrained cells by the 30th LS and occluded any additional spike frequency reductions in Paired cells. (A) Representative light responses recorded from an Untrained B cell injected with PP1 buffer (Unt + PP1 Buffer; top trace) or caPP1 (Unt + PP1; bottom trace). The Unt + PP1 Buffer control cell showed a slight increase in spike frequency from the 5 th to 30th LS, while the Unt + PP1 cell showed a progressive $23 \%$ decrease in spike frequency that mimicked the decreases observed in Paired (no drug) cells, i.e., in vitro extinction. Inset traces show last $10 \mathrm{~s}$ of LS. (B) Summary spike frequency data for Untrained and Untrained + PP1 Buffer control cells across 30 LSs. Note the slight excitatory effect of the buffer. (C) Summary spike frequency data for 30 successive LSs indicated that Unt $+P P 1$ cells showed qualitatively lower spike frequencies during LSs 16-30 compared to Unt + PP1 Buffer and Untrained controls, and were no different than Paired (no drug) cells, thereby producing spike frequency reductions similar to those observed during in vitro extinction.
B
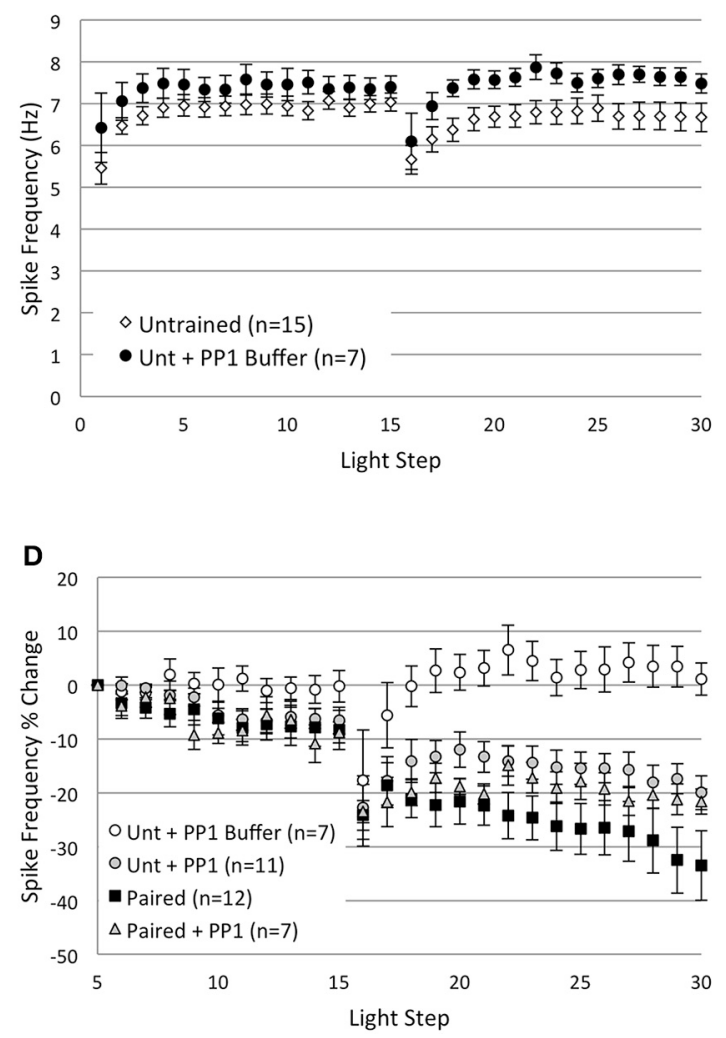

Paired cells injected with caPP1 (Paired + PP1) showed significant decreases in spike frequency below Unt + PP1 Buffer control cells. These reductions were no larger than those observed in Paired (no drug) cells, suggesting that caPP1 injection occluded any further spike frequency reductions produced by repetitive LSs. (D) Summary data of the relative percent change in B cell spike frequency from the 5th to 30th LS. Unt + PP1 cells exhibited significant declines in spike frequency from the 5th to 30th LS ( 20\%) compared to Unt + PP1 Buffer (1\% increase) control cells. These decreases observed in Unt $+P P 1$ cells were not statistically different than the spike frequency reductions observed in Paired (no drug) cells, suggesting that caPP1 is able to produce decreases in spike frequency that are similar in magnitude and time course to the reductions produced by in vitro extinction. caPP1 injection into Paired cells produced decreases in spike frequency that occluded any further decreases produced by repeated LSs in Paired (no drug) cells ( 22\% vs. $\sim 34 \%$, respectively), suggestive of an occlusion effect. Error bars are \pm s.e.m. and significant $p$-values are $<0.05$

\section{CYCLOSPORIN A BLOCKS THE EFFECTS OF IN VITRO EXTINCTION}

To further probe the link between repeated LSs and PP1 activation, we investigated an upstream regulator of PP1, protein phosphatase $2 \mathrm{~B}$ ( $\mathrm{PP} 2 \mathrm{~B}$, aka calcineurin). $\mathrm{PP} 2 \mathrm{~B}$ is a $\mathrm{Ca}^{2+} /$ calmodulin-dependent phosphatase (Stemmer and Klee, 1994) that positively regulates PP1 in many cells through the dephosphorylation of inhibitor-1 and the subsequent disinhibition of PP1 (Mulkey et al., 1994). Because repeated LSs can lead to an accumulation of intracellular $\mathrm{Ca}^{2+}$ in (untrained) Type B cells, which constrains associative learning in a phosphatase-dependent manner (Muzzio et al., 1999), we hypothesized that the repeated LSs used during in vitro extinction would also activate PP2B in Paired cells, leading to the disinhibition of PP1 and reductions in B cell spike frequency. To test this hypothesis, B cells from Paired or Untrained animals were injected with cyclosporin A, a $\mathrm{PP} 2 \mathrm{~B}$-specific inhibitor, and then exposed to in vitro extinction. If the extinction-produced reduction in B cell spike frequency requires $\mathrm{PP} 2 \mathrm{~B}$ activity, then the addition of cyclosporin to Paired cells prior to in vitro extinction should block the decrease. In support of this hypothesis, cyclosporin injection into Paired cells blocked the progressive decrease in spike frequency observed during in vitro extinction, but had no effect on spike frequency in Untrained cells (Figure 6).

Cyclosporin had small (non-significant) facilitatory effects on spike frequencies during LSs 1-2 for both Untrained (Untrained + Cyclosporin; $n=5 ; 6.48 \pm 0.36 \mathrm{~Hz}$ ) and Paired (Paired + 
A
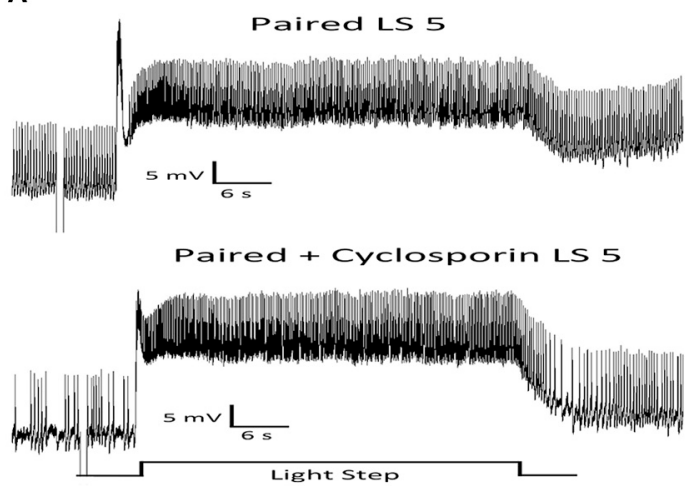

B

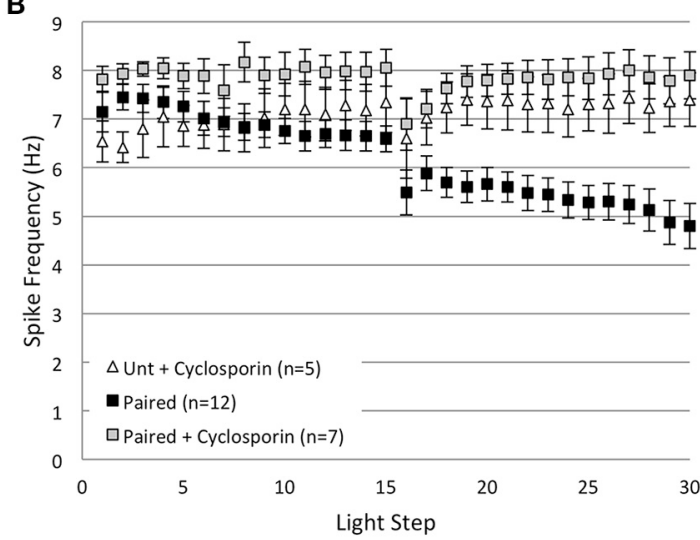

FIGURE 6 | Injection of cyclosporin A (100 nM in electrode) into Paired Type $B$ cells at the start of in vitro extinction blocked the progressive reduction in spike frequency produced by repeated LSs in Paired cells. (A) Representative light responses recorded from a Paired Type B cell (top trace) and a Paired cell incubated in cyclosporin A (Paired + Cyclosporin; bottom trace). The Paired cell showed a clear decrease in spike frequency from the 5th to 30th LS, while the Paired + Cyclosporin cell exhibited no change. (B) Summary spike frequency data over 30 LSs of Type B cells injected with cyclosporin. The progressive reduction in spike frequency exhibited by Paired (no drug) cells during LSs $16-30$ was abolished when
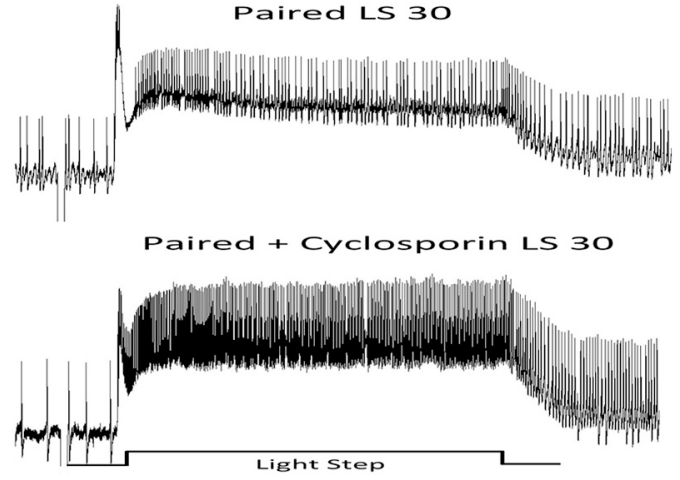

C

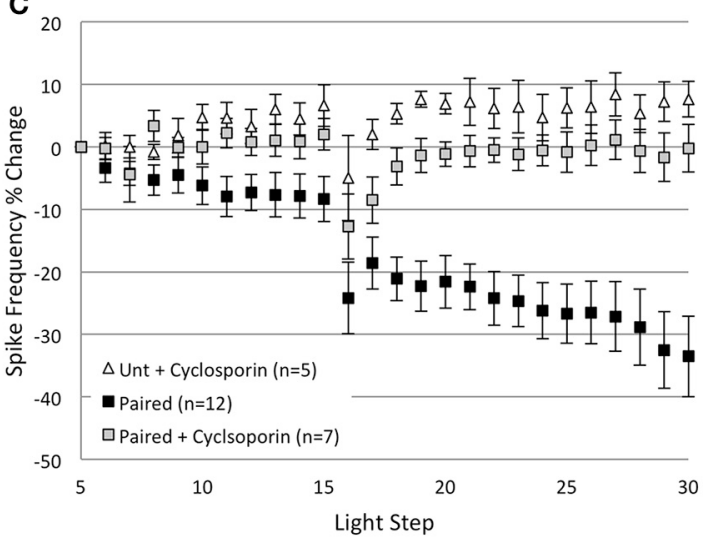

Paired cells were injected with cyclosporin prior to in vitro extinction. Spike frequencies of Paired + Cyclosporin cells were no different than Untrained cells injected with cyclosporin (Unt + Cyclosporin). (C) Summary data of the relative percent change in $B$ cell spike frequencies from the 5th to 30th LS. Injection of Paired cells with cyclosporin prevented the large decrease in spike frequency over the course of 30 LSs observed in Paired cells without drug (0\% change vs. $\sim 34 \%$ decrease, respectively). The spike frequency changes of Paired + Cyclosporin cells over the course of 30 LSs were indistinguishable from those observed in Unt + Cyclosporin cells. Error bars are \pm s.e.m.
Cyclosporin; $n=7 ; 7.87 \pm 0.23 \mathrm{~Hz})$ cells. This suggests that constitutive activity of endogenous PP2B, and off-target effects of cyclosporin on B cell excitability, were low-to-negligible. During LSs 16-30, cyclosporin blocked the progressive decrease in spike frequencies produced by in vitro extinction in Paired cells. Paired + Cyclosporin cells spiked significantly more frequently than Paired (no drug) cells $\left[F_{(1,17)}=18.35, p=0.001\right]$ (Figures 6A,B). The spike frequency of Paired + Cyclosporin cells was greater than Untrained cells $\left[F_{(1,20)}=5.12, p=0.035\right]$, but no different than Untrained + Cyclosporin control cells $\left[F_{(1,10)}=\right.$ $0.52, p=0.486]$ (Figure 6B). Untrained + Cyclosporin cells were not different from Untrained (no drug) cells $\left[F_{(1,18)}=1.23\right.$, $p=0.282]$.

Similar conclusions concerning the effects of cyclosporin followed from analysis of the relative changes in spike frequency from the 5th to 30th LS (Figure 6C). Paired + Cyclosporin cells failed to show the progressive declines in spike frequency normally produced without drug, and instead showed a small
$0.2 \pm 3.8 \%$ decline compared to Paired (no drug) cells (33.5 \pm $6.5 \%$ decrease) $\left[F_{(1,17)}=13.82, p=0.002\right]$ (Figure 6C). The negligible spike frequency decrease of Paired + Cyclosporin cells was not significantly different from Untrained (no drug) cells $(2.6 \pm 5.98 \%$ decrease $)\left[F_{(1,20)}=0.02, p=0.878\right]$, or Untrained + Cyclosporin cells $\left(7.6 \pm 2.83 \%\right.$ increase) $\left[F_{(1,10)}=\right.$ $3.29, p=0.10]$ (Figure 6C).

In summary, the injection of cyclosporin into B cells prior to in vitro extinction blocked the progressive reduction in B cell spike frequencies produced by repeated LSs, suggesting that PP2B participates in the extinction-produced spike frequency decreases in B cells.

\section{PROTEIN PHOSPHATASE 2B PREVENTS THE SPIKE FREQUENCY DECREASES IN PAIRED CELLS DUE TO IN VITRO EXTINCTION BUT MIMICS THE EFFECTS OF IN VITRO EXTINCTION IN UNTRAINED CELLS}

If endogenous PP2B mediates the decreased B cell spike frequencies observed during in vitro extinction, then the injection of 
exogenous caPP2B into Paired cells would be expected to produce a decrease in spiking that occludes any further decreases elicited by the repeated LSs. Prediction of the effects of caPP2B injection into Untrained cells is less clear. If PP2B acts exclusively through disinhibition of PP1, but PP1 is either not part of the $\mathrm{K}^{+}$signaling complex and/or the $\mathrm{K}^{+}$channels are not appreciably serine/threonine-phosphorylated in the basal (untrained) state, then injection of caPP2B might not significantly affect spike frequency. Alternatively, if endogenous PP1 is targeted to $\mathrm{K}^{+}$channel signaling complexes and the $\mathrm{K}^{+}$channels are serine/threonine-phosphorylated in Untrained cells, then injection of the caPP2B could activate PP1, dephosphorylate $\mathrm{K}^{+}$channels (or associated proteins), enhance $\mathrm{K}^{+}$currents, and decrease spike frequencies similar to that produced by in vitro extinction. To test these hypotheses, we injected caPP2B into B cells from Untrained or Paired-trained animals prior to in vitro extinction.
Counter to our expectations, caPP2B injection into Paired cells did not decrease spike frequencies, but instead prevented the reduction in spiking normally produced by in vitro extinction (Figure 7). In contrast, the injection of caPP2B into Untrained cells reduced spike frequencies over the course of 30 LSs, which was very similar to the decreases observed during in vitro extinction for Paired cells (without caPP2B).

caPP2B injection had no appreciable effect on spike frequency during LSs 1-2 for either Untrained (Untrained + PP2B; $n=11 ; 6.04 \pm 0.33 \mathrm{~Hz}$ ) or Paired cells (Paired + PP2B; $n=7 ; 7.50 \pm 0.28 \mathrm{~Hz}$ ). PP2B buffer (Buffer control; $n=6$; $5.83 \pm 0.35 \mathrm{~Hz}$ ) also had no effect on spike frequency during LSs 1-2. During LSs 16-30, Paired $+P P 2 B$ cells showed spike frequencies that were significantly elevated compared to Paired (no drug) cells $\left[F_{(1,17)}=16.71, p=0.001\right]$, and slightly (non-significantly) above Buffer control levels $\left[F_{(1,11)}=4.37\right.$,
A

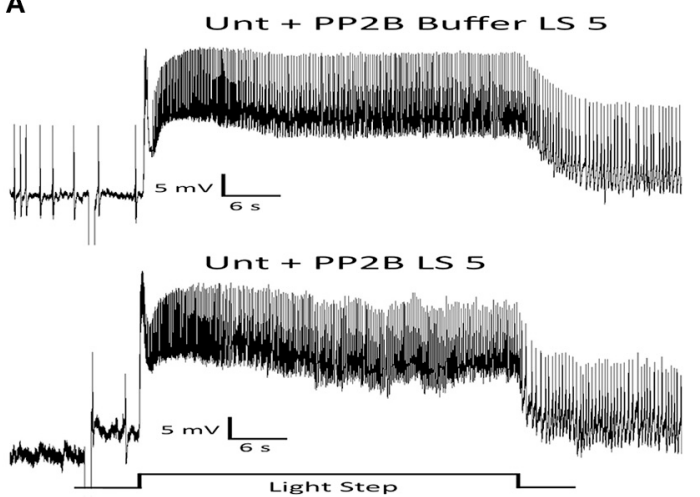

B

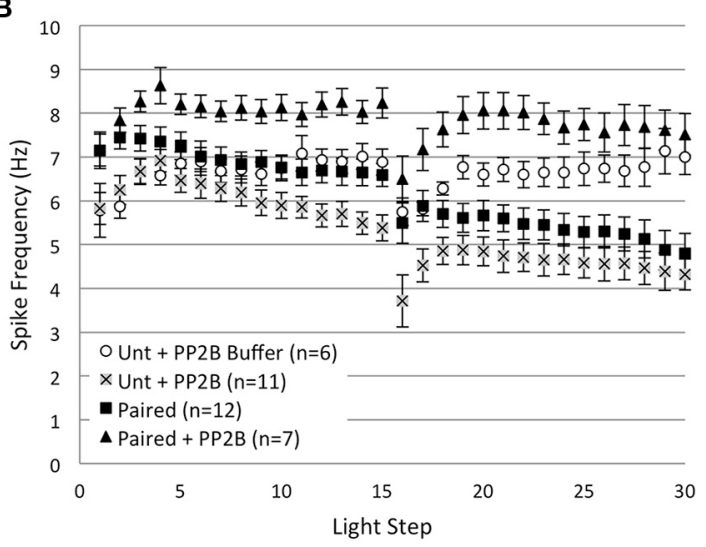

FIGURE 7 | Injection of catalytically active protein phosphatase 2B (caPP2B) into Paired Type B cells prevented the decrease in light-evoked spike frequency produced by repeated LSs, and reduced spike frequencies when injected into Untrained cells. (A) Representative light responses recorded from an Untrained $B$ cell injected with PP2B buffer (Unt + PP2B Buffer; top trace) or caPP2B (Unt + PP2B; bottom trace). The Unt + Buffer control cell showed no change in spike frequency from the 5 th to 30th LS, while the Unt $+P P 2 B$ cell showed a progressive decrease in spike frequency that mimicked the decreases observed during in vitro extinction in Paired (no drug) cells. (B) Summary spike frequency data across 30 LSs for Type B cells exposed to buffer or caPP2B. Paired + PP2B cells did not show decreases in spike frequency and spiked at levels not statistically
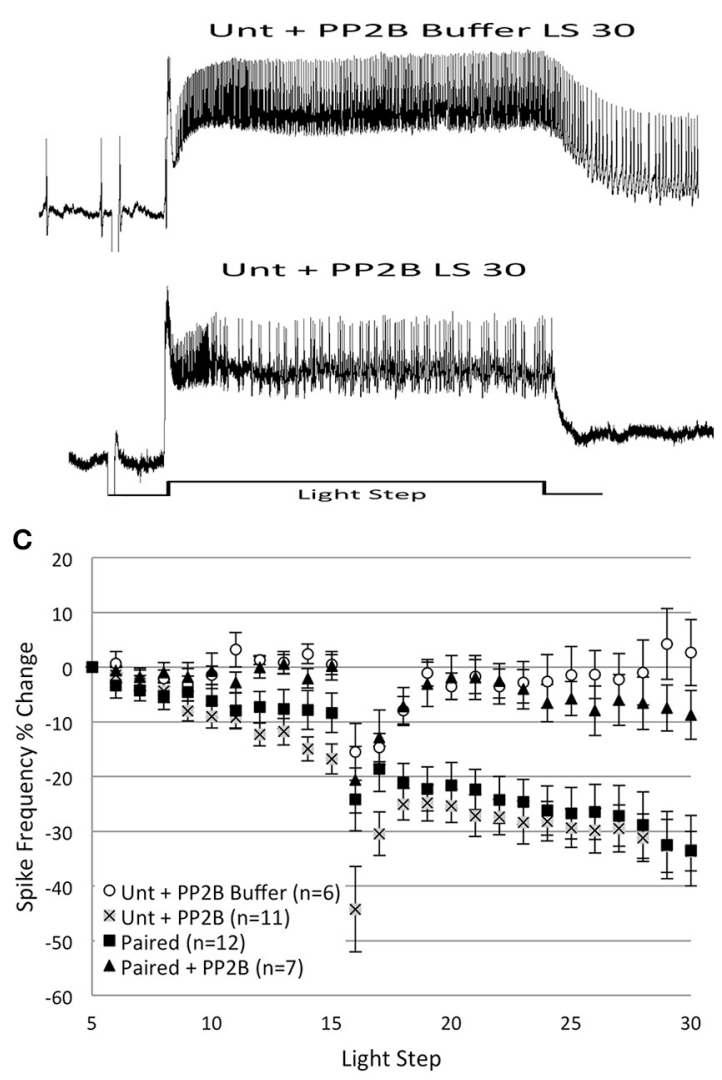

different from Unt + PP2B Buffer control cells. In contrast, Unt $+P P 2 B$ cells showed significantly lower spike frequencies during LSs 16-30 compared to Unt + PP2B Buffer controls, and were no different than Paired (no drug) cells. (C) Summary data of the relative percent change in B cell spike frequencies from the 5th to 30th LS. Injection of caPP2B into Paired cells blocked the large reduction in spike frequency observed in Paired (no drug) cells; Paired $+P P 2 B$ cells showed significantly smaller decreases in spike frequencies ( $9 \%$ ) over the course of 30 LSs. Unt $+P P 2 B$ cells exhibited significant decreases in spike frequencies from the 5th to 30th LS ( 34\%), which mimicked the substantial reductions produced by repeated LSs in Paired (no drug) cells ( 34\%), except that they occurred sooner. Error bars are \pm s.e.m. and significant $p$-values are $<0.05$. 
$p=0.06]$ (Figure 7B). When measured as a percent change in spike frequencies from the 5 th to 30 th LS, Paired $+P P 2 B$ cells exhibited a $8.7 \pm 4.1 \%$ decrease in spiking that was significantly less than Paired (no drug) cells $\left(33.5 \pm 6.5 \%\right.$ decrease) $\left[F_{(1,17)}=\right.$ $8.11, p=0.011]$, and no different from Buffer cells $(2.6 \pm 6.0 \%$ increase) $\left[F_{(1,11)}=0.46, p=0.514\right]$ (Figure 7C).

In contrast, Untrained $+P P 2 B$ cells showed a progressive reduction in spike frequencies throughout LSs 16-30 that was no different from the decreases observed in Paired (no drug) cells $\left[F_{(1,21)}=2.71, p=0.114\right]$, but was significantly greater than Untrained $\left[F_{(1,24)}=20.03, p=0.000\right]$ and Buffer $\left[F_{(1,15)}=\right.$ 14.75, $p=0.002$ ] cells (Figure 7B). Analysis of the percent change in spike frequencies from the 5 th to 30 th LS yielded similar results. Untrained $+P P 2 B$ cells showed a large $33.6 \pm 3.6 \%$ reduction in spiking that was no different than Paired (no drug) cells $\left(33.5 \pm 6.5 \%\right.$ decrease) $\left[F_{(1,21)}=0.89, p=0.358\right]$ (Figure 7C).

In summary, these results partially support the hypothesis that $\mathrm{PP} 2 \mathrm{~B}$ participates in the reduction in spike frequencies produced by in vitro extinction. caPP2B injection into Untrained cells decreased spike frequencies, mimicking the effects of in vitro extinction. Unexpectedly, injection of caPP2B into Paired cells did not decrease spike frequencies and blocked the spiking reductions produced by in vitro extinction.

\section{CALYCULIN A PREVENTS THE DECREASE IN SPIKE FREQUENCY PRODUCED BY PROTEIN PHOSPHATASE 2B IN UNTRAINED CELLS}

The progressive reduction of spike frequencies produced by in vitro extinction in Paired cells appears to depend upon both PP2B and PP1, because inhibitors of either phosphatase blocked the spiking reductions. To further probe possible interactions between the two phosphatases, we used calyculin A to block endogenous PP1 activity and injected caPP2B into cells from Untrained animals prior to in vitro extinction. If the reduction of spike frequency produced by $\mathrm{caPP} 2 \mathrm{~B}$ occurs through the activation of PP1, then prior incubation in calyculin should block this spiking decrease. This is what we observed (Figures 8B-D).

The combination of caPP2B and calyculin appeared to produce a general facilitatory effect on spike frequencies. An ANOVA of LSs 1-2 showed a significant main effect of treatment condition for Untrained $+P P 2 B+$ Calyculin $(n=8)$, Untrained + Calyculin $(n=7)$, Untrained $+P P 2 B(n=11)$, and Paired $(n=11)$ groups $\left[F_{(3,33)}=5.74, p=0.003\right]$ (Figure 8A). Posthoc analysis revealed that spike frequencies of Untrained + $P P 2 B+$ Calyculin cells $(7.97 \pm 0.47 \mathrm{~Hz})$ were significantly greater than Untrained $+P P 2 B$ cells $(6.04 \pm 0.33 \mathrm{~Hz})(p=0.018)$ and Untrained + Calyculin cells $(5.79 \pm 0.69 \mathrm{~Hz})(p=0.016)$, but were not different from Paired (no drug) cells $(7.44 \pm 0.31 \mathrm{~Hz})$ $(p=1.0)$ (Figure 8A). These data indicated that Untrained + $P P 2 B+$ Calyculin cells enhanced excitability during LSs $1-2$ to levels characteristic of Paired cells.

During LSs 16-30, calyculin blocked the reduction in spike frequencies produced by caPP2B injection, and spiking of Untrained $+P P 2 B+$ Calyculin cells was not different than Untrained + Calyculin cells $\left[F_{(1,13)}=3.28, p=0.093\right]$, but was significantly greater than Untrained $+P P 2 B$ cells $\left[F_{(1,17)}=\right.$ 40.27, $p=0.000$ ] (Figures 8B,C). This block of caPP2B's effects was not a result of general increases in spiking, as similar results were found when spike frequencies were analyzed as a relative percent change from the 5 th to 30 th LS (Figure 8D). Untrained + $P P 2 B+$ Calyculin cells showed a $5.3 \pm 4.6 \%$ decrease in spike frequency by the 30th LS that was not significantly different from Untrained + Calyculin cells $(10.8 \pm 12.5 \%$ increase $)\left[F_{(1,13)}=\right.$ $3.35, p=0.090]$, but was significantly different from Untrained + $P P 2 B$ cells $(33.6 \pm 3.6 \%$ decrease $)\left[F_{(1,17)}=23.61, p=0.000\right]$ (Figure 8D).

In summary, caPP2B did not reduce B cell spike frequencies when endogenous PP1 was inhibited. These results support the view that the reduction in Untrained cell spike frequencies produced by caPP2B injection was mediated (at least partly) through endogenous PP1. The combination of calyculin and caPP2B also enhanced spike frequencies of Untrained cells during LSs 1-2 to levels comparable to Paired cells, suggesting that that caPP2B may have both excitatory and inhibitory effects on B cell spike frequency. When the latter effects were blocked by calyculin, the excitatory effects were unmasked. Our results indicate that the PP1 and PP2B pathways interact to reduce spike frequencies in Untrained cells to levels observed during in vitro extinction in Paired cells.

\section{ARACHIDONIC ACID OCCLUDES ADDITIONAL SPIKE FREQUENCY DECREASES PRODUCED BY EXTINCTION IN PAIRED CELLS AND MIMICS THE EFFECTS OF IN VITRO EXTINCTION IN UNTRAINED CELLS}

Previous data from our lab indicates that AA and one of its principle metabolites, 12(S)-HPETE, contribute to the decrease in Type B cell excitability produced by inhibitory conditioning (Walker et al., 2010). Because AA and 12(S)-HPETE both elicit decreases in B cell light-evoked spike frequencies (similar to the effect of in vitro extinction), we hypothesized that these molecules might also be recruited during in vitro extinction. To test this, we bath applied AA onto Untrained and Paired cells during administration of in vitro extinction. AA was added to the bath solution after the 5th LS, once spike frequencies had stabilized (as in Walker et al., 2010). If AA is involved in the spike frequency reduction observed during in vitro extinction, then the decreases in spiking produced by exogenous AA should occlude further decreases in spike frequencies by repeated LSs in Paired cells. In support of this idea, the addition of AA to Paired cells produced a reduction in spike frequency that was no larger than the decreases observed in Paired (no drug) cells (Figure 9).

Because AA was added after LS 5, an analysis of AA's effects on LSs 1-2 was precluded. During LSs 16-30, application of AA to Paired cells (Paired $+A A ; n=13$ ) produced a reduction in spike frequencies that was below Solvent control cell $(n=7)$ levels, and became larger over time [significant interaction between LS and condition, corrected for sphericity: $F_{(2.86,51.42)}=5.78, p=$ 0.002] (Figure 9B). The reduction in spike frequency observed in Paired $+A A$ cells was slightly (non-significant) less than the reductions produced in Paired (no drug) cells $\left[F_{(1,23)}=3.55\right.$, $p=0.072$ ] (Figure 9B). Analysis of the percent change in spike frequencies from the 5th to 30th LS further supported these conclusions. Paired $+A A$ cells exhibited a $22.3 \pm 2.7 \%$ decrease in spike frequencies that was significantly greater than Solvent control cells $(3.0 \pm 3.2 \%$ increase $)\left[F_{(1,18)}=11.70, p=0.003\right]$, but 

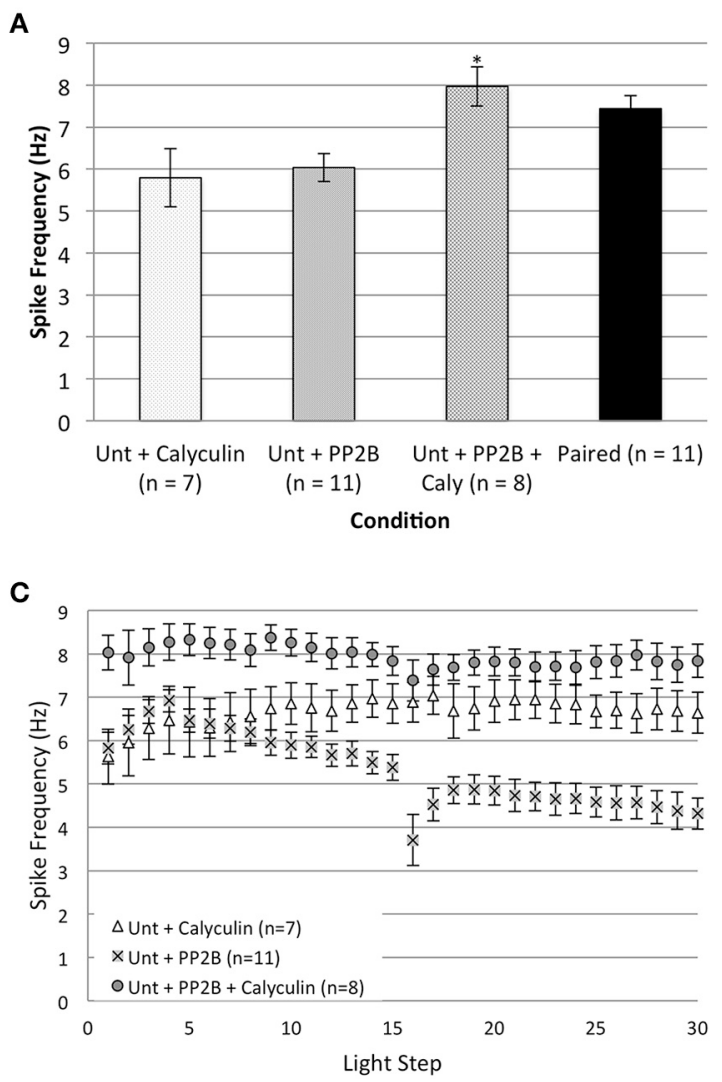

FIGURE 8 | The incubation of Untrained Type B cells in calyculin A ( $20 \mathrm{nM}$ final bath concentration) for $15 \mathrm{~min}$ prevented the reduction in spike frequency produced by injection of catalytically active PP2B (caPP2B) and increased spiking during the first two LSs. (A)

Summary data for average light-evoked spike frequencies during the first two LSs. The combination of caPP2B and calyculin in Untrained cells produced higher spike frequencies compared to cells exposed to either caPP2B or calyculin alone. (B) Representative light responses recorded from an Untrained B cell injected with caPP2B (Unt + PP2B group; top trace) and an Untrained cell injected with caPP2B in the presence of calyculin (Unt + PP2B + Calyculin; bottom trace). The Unt + PP2B cell showed a large reduction in spike frequencies over the course of 30 LSs. Calyculin blocked this caPP2B-produced reduction in spike frequency.
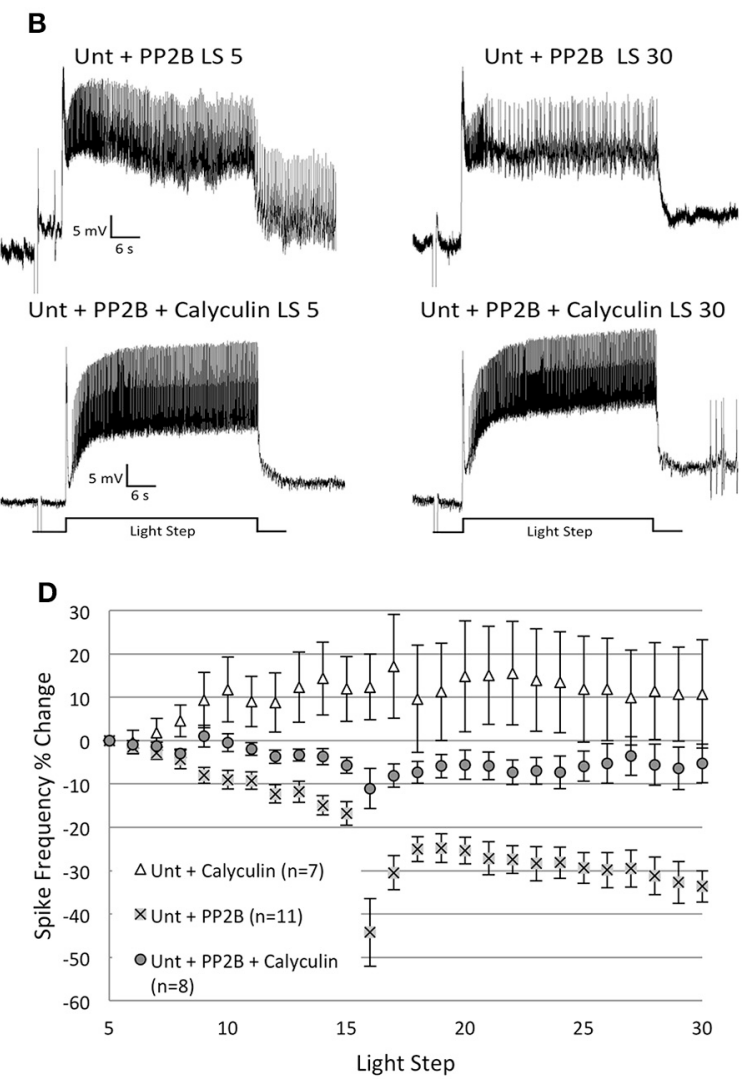

(C) Summary spike frequency data for Type B cells exposed to caPP2B and calyculin across 30 LSs. Unt $+P P 2 B$ cells showed significantly lower spike frequencies during LSs 16-30 compared to Unt + Calyculin cells. In contrast, Unt $+P P 2 B+$ Calyculin cells showed a slight increase (non-significant) in spike frequencies compared to Unt + Calyculin cells, and were significantly elevated relative to Unt + PP2B cells. (D)

Summary data of the relative percent change in $B$ cell spike frequencies from the 5th to 30th LS. Unt + PP2B cells exhibited significant decreases in spike frequency from the 5 th to 30 th LS ( 34\%), while Unt $+P P 2 B$ + Calyculin cells showed very little decrease ( $5 \%$ ) over the course of 30 LSs. Note that data for Unt + Calyculin and Unt + PP2B cells shown here have been replotted from Figures 4, 7. Error bars are \pm s.e.m. and significant $p$-values ( $p$ 's $<0.05$ ) are denoted by an asterisk. not significantly different from Paired (no drug) cells (33.5 \pm $6.5 \%$ decrease) $\left[F_{(1,23)}=2.07, p=0.163\right]$ (Figure 9C).

As expected (Walker et al., 2010), the addition of AA to Untrained cells (Untrained $+A A ; n=7$ ) produced a decrease in spike frequency that mimicked the reductions produced by in vitro extinction. Compared to Solvent controls, Untrained + $A A$ cells showed progressive reductions in spike frequencies during LSs 16-30 [significant interaction between LS and condition: $F_{(14,168)}=3.72, p=0.000$ ] (Figures 9A,B). The reduced spike frequencies observed in Untrained $+A A$ cells were indistinguishable from Paired (no drug) cells $\left[F_{(1,17)}=2.02, p=0.174\right]$ (Figure 9B). The effects of AA were more pronounced when considered as a percent change in spiking from the 5th to 30th LS. Untrained $+A A$ cells exhibited a $23.0 \pm 4.1 \%$ decrease in spike frequency by the 30th LS, which was significantly greater than Solvent control cells $(3.0 \pm 3.2 \%$ increase $)\left[F_{(1,12)}=14.25, p=\right.$
0.003], and not significantly different from Paired (no drug) cells $\left(33.5 \pm 6.5 \%\right.$ decrease) $\left[F_{(1,17)}=1.86, p=0.191\right]$ (Figure 9C).

These findings suggest that AA might be one molecule responsible for the in vitro extinction-produced decreases in spike frequency. Not only did AA addition to Untrained cells mimic the effects of in vitro extinction, but the addition of AA to Paired cells also occluded any further declines in spike frequency produced by in vitro extinction, suggesting that they are part of a common signaling pathway.

\section{BAICALEIN, AN INHIBITOR OF 12(S)-HPETE PRODUCTION, BLOCKS IN VITRO EXTINCTION}

Our previous research (Walker et al., 2010) found that AAproduced reductions in B cell spike frequency were mainly a result of 12(S)-HPETE, an AA metabolite produced by the 12lipoxygenase (12-LOX) enzyme. We therefore hypothesized that 


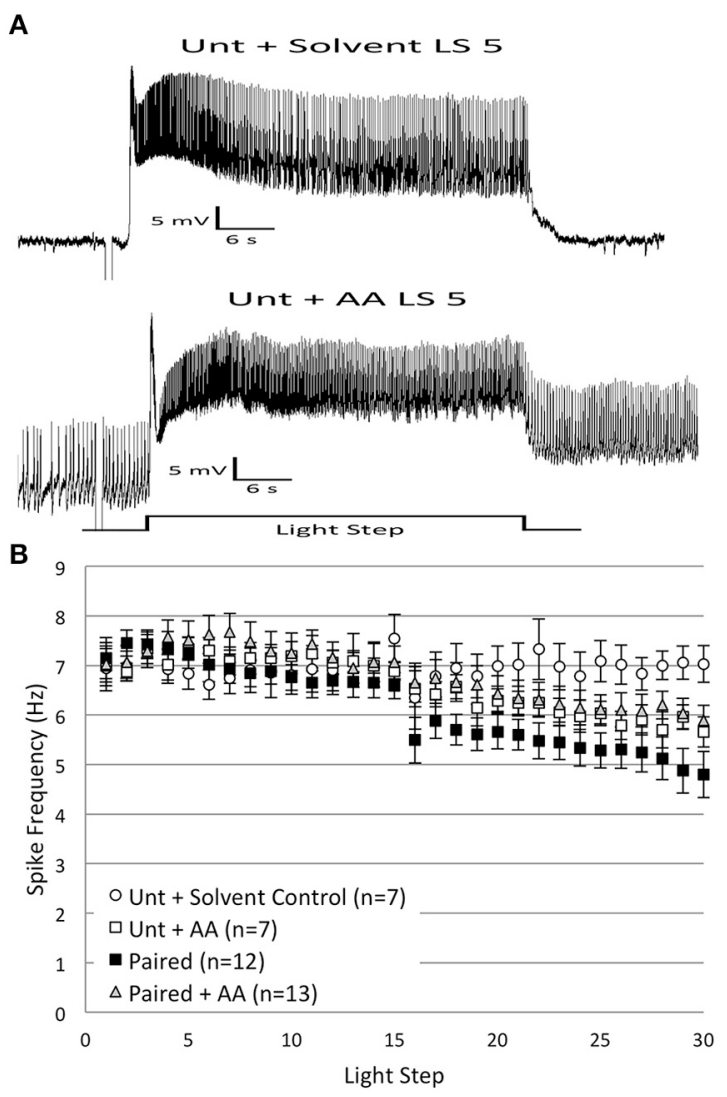

FIGURE 9 | Bath application of arachidonic acid (AA; $100 \mu \mathrm{M}$ ) onto Paired Type $B$ cells reduced $B$ cell spike frequency and occluded any further decreases produced by in vitro extinction. $A A$ applied to Untrained B cells produced reductions in spike frequency that mimicked the decreases observed in Paired (no drug) cells. AA or vehicle solvent (ethanol, $0.1 \%$ final bath concentration) was bath applied to exposed H.C. nervous systems immediately after the 5th LS. (A) Representative light responses recorded from an Untrained Type B cell exposed to solvent (Unt + Solvent; top trace) or AA (Unt $+A A$; bottom trace). (B) Summary spike frequency data of Type $B$ cells exposed to AA or solvent over 30 LSs. Paired $+A A$ cells exhibited a decrease in spike frequency compared to Unt + Solvent control cells (significant interaction between LS and condition). The significant reduction in spike frequencies produced in Paired $+A A$ cells was as large, but no larger, than the decrease produced in
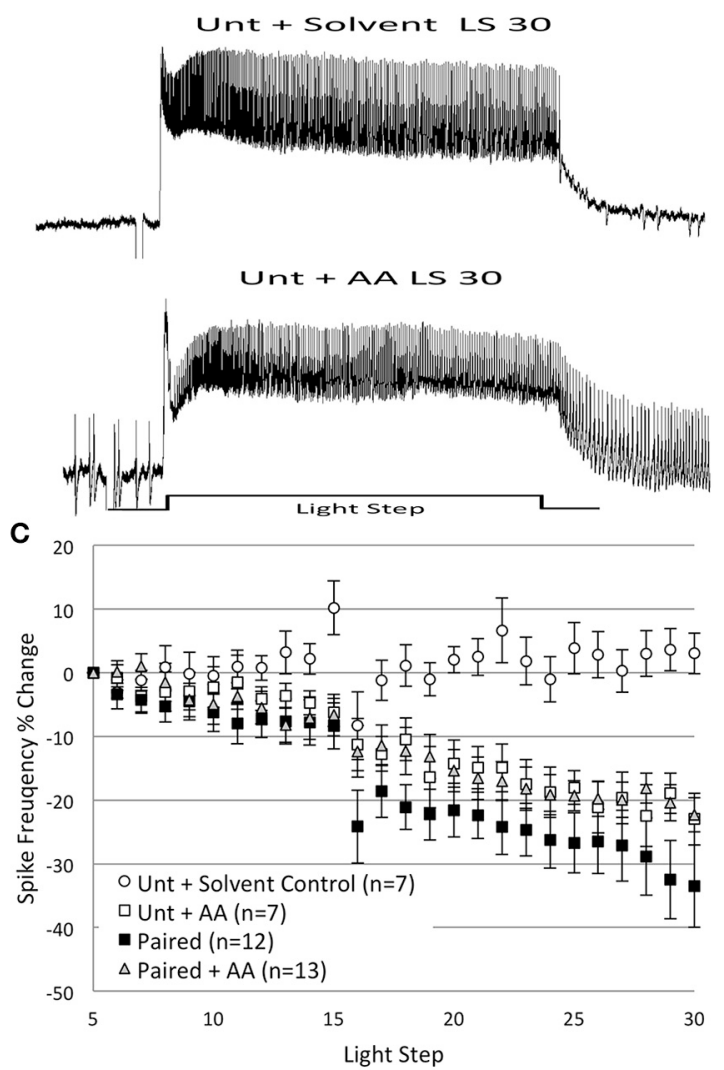

Paired (no drug) cells, which suggests that AA occluded the spike frequency reducing effects of repeated LSs in Paired (no drug) cells. The application of AA to Untrained cells mimicked the effects of in vitro extinction and produced reductions in spike frequency that were significantly below levels observed in Unt + Solvent control cells. (C) Summary data of the relative percent change in $B$ cell spike frequency from the 5 th to 30th LS. Paired $+A A B$ cells exhibited a significant decline $(\sim 22 \%)$ in spike frequency over the course of 30 LSs, which was significantly larger than the small changes observed in Unt + Solvent control cells (3\% increase), but not statistically different from the decreases seen in Paired (no drug) cells ( $34 \%)$. Unt $+A A$ cells also showed significantly larger declines in spike frequency $(\sim 23 \%)$ compared to Unt + Solvent controls, and these decreases were not statistically different from Paired (no drug) cells. Error bars are \pm s.e.m. and significant $p$-values are $<0.05$.
12(S)-HPETE might also be a critical metabolite for in vitro extinction. We predicted that baicalein, a selective inhibitor of the 12-LOX enzyme, would block the decrease in spike frequency produced by in vitro extinction. To test this idea, we incubated Untrained and Paired cells in baicalein for $10 \mathrm{~min}$ prior to the administration of in vitro extinction. Consistent with our hypothesis, baicalein significantly blunted the decreases in B cell spike frequency observed in Paired cells, but had little impact on Untrained cells (Figure 10).

Incubation of Untrained and Paired cells in baicalein (Untrained + Baicalein, $n=7,7.06 \pm 0.36 \mathrm{~Hz}$; Paired + Baicalein, $n=7,6.89 \pm 0.61 \mathrm{~Hz}$ ) did not alter spike frequencies during LSs 1-2. In contrast, baicalein had a profound effect during LSs 16-30, but only for Paired cells. Paired +
Baicalein cells failed to show the progressive decline in spike frequency during LSs $16-30$ and spiked at rates significantly greater than Paired (no drug) cells $\left[F_{(1,17)}=9.17, p=0.008\right]$ (Figure 10A), but were no different than Untrained $\left[F_{(1,20)}=\right.$ $0.46, p=0.504]$ or Untrained + Baicalein cells $\left[F_{(1,12)}=0.02\right.$, $p=0.897]$ (Figure 10B). This blockade of the reduction in spike frequency was not a result of non-specific increases in spiking, as spike levels of Untrained + Baicalein cells during LSs 16-30 were not different from levels exhibited by Untrained (no drug) cells $\left[F_{(1,20)}=0.65, p=0.428\right]$. Similar conclusions concerning the effects of baicalein were reached when considered as a percent change in spike frequencies from the 5th to 30th LS. Paired + Baicalein cells showed a $6.8 \pm 0.7 \%$ reduction in spike frequency, which was significantly less than Paired (no drug) cells (33.5 \pm 
A
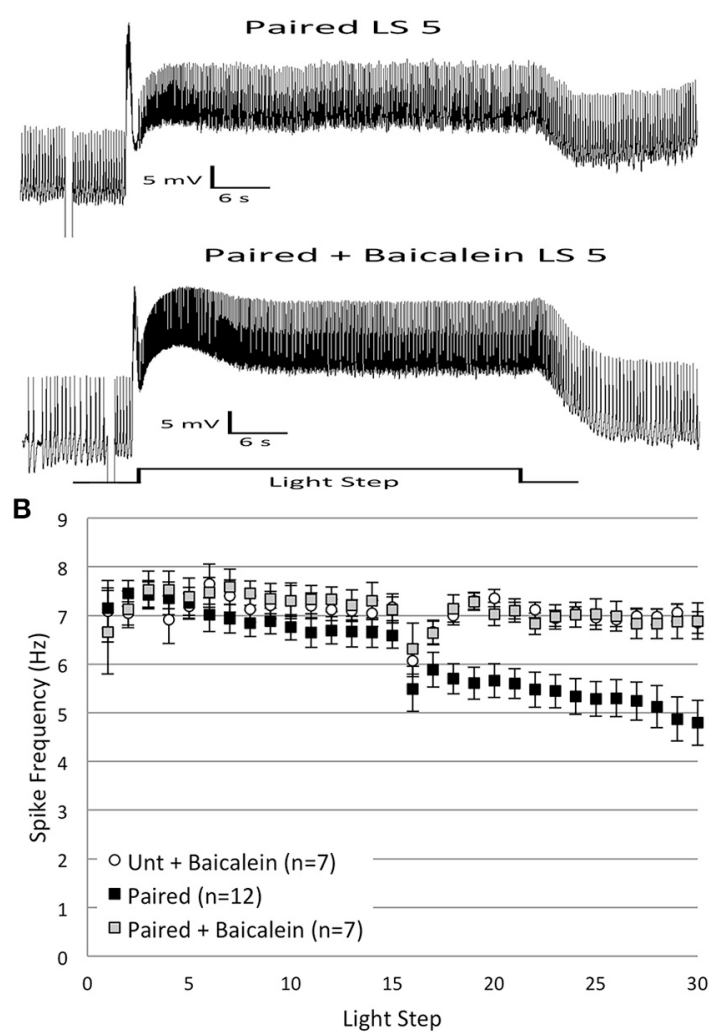

FIGURE 10 | Incubation of Paired Type B cells in baicalein $(100 \mu \mathrm{M}$ final bath concentration) for $10 \mathrm{~min}$ prior to in vitro extinction blocked the reduction in spike frequency produced by repeated LSs in Paired (no drug) cells. (A) Representative light responses recorded from a Paired Type B cell (top trace) and a Paired cell incubated in baicalein (Paired + Baicalein; bottom trace). The Paired cell showed a clear decline in spike frequency from the 5th to 30th LS, while the Paired + Baicalein cell did not. (B) Summary spike frequency data of Type B cells exposed to baicalein. The significant decrease in spike
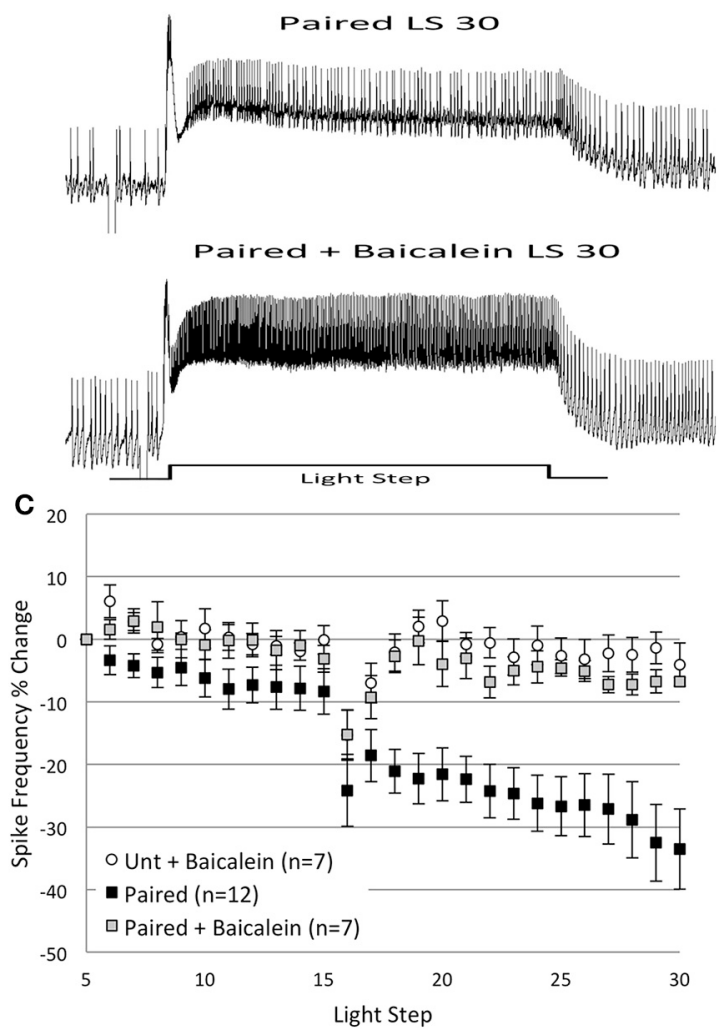

frequency seen in Paired (no drug) cells during LSs 16-30 was prevented by prior incubation in baicalein. Spike frequencies of Paired + Baicalein cells were no different than Untrained cells incubated in baicalein (Unt + Baicalein). (C) Summary data of the percent change in B cell spike frequency from the 5th to 30th LS. The incubation of Paired cells in baicalein blocked the large decrease in spike frequency over the course of 30 LSs observed in Paired (no drug) cells, and Paired + Baicalein cells spiked at frequencies not statistically different from Unt + Baicalein cells. Error bars are \pm s.e.m. and significant $p$-values are $<0.05$.
$6.5 \%$ decrease) $\left[F_{(1,17)}=10.46, p=0.005\right]$, yet no different than Untrained (no drug) cells $\left(2.6 \pm 6.0 \%\right.$ decrease) $\left[F_{(1,20)}=0.09\right.$, $p=0.772]$, nor from Untrained + Baicalein cells $(4.1 \pm 3.5 \%$ decrease) $\left[F_{(1,12)}=0.79, p=0.393\right]$ (Figure 10C).

In summary, baicalein blocked the reduction in spike frequency produced by repeated LSs in Paired cells, yet had no effect in Untrained cells. These findings support the hypothesis that 12(S)-HPETE is involved in mediating the reduction of B cell spike frequency observed during in vitro extinction.

\section{CALYCULIN DOES NOT BLOCK THE EFFECTS OF ARACHIDONIC ACID}

Precedents exist for an interaction between AA/lipoxygenase metabolites, protein phosphatases, and $\mathrm{K}^{+}$channels (e.g., Duerson et al., 1996). Because the addition of exogenous caPP1 and AA both separately reduced B cell spike frequencies over the course of 30 LSs in Untrained cells, we wondered if they did so by participation in the same, or different, signaling pathway(s). To investigate these possibilities, we exposed $\mathrm{B}$ cells to AA in the presence of the PP1 inhibitor, calyculin A. B cells were first incubated in calyculin for $15 \mathrm{~min}$, followed by the bath application of AA after the 5th LS. If the spike frequency decreases produced by AA are mediated through a PP1-dependent pathway, then incubation of $\mathrm{B}$ cells in calyculin prior to $\mathrm{AA}$ addition should prevent/attenuate the reduction in spike frequency. Our results failed to support this view. We found instead that calyculin did not block the reductions in spike frequency produced by AA and actually led to greater reductions in spiking (Figure 11) than AA-alone.

Untrained cells incubated in calyculin and exposed to AA (Untrained + Calyculin $+A A ; n=6)$ showed marked reductions in spike frequencies during LSs $16-30$ that were significantly below levels observed in Untrained + Calyculin $\left[F_{(1,11)}=\right.$ $10.14, p=0.009]$, and AA vehicle Solvent control cells $\left[F_{(1,11)}=\right.$ $11.69, p=0.006$ ] (Figure 11B). This reduction was significantly greater than that observed in Untrained $+A A$ cells $\left[F_{(1,11)}=\right.$ $6.75, p=0.025]$ (Figures 11A,B), and was no different than the reductions observed in Paired (no drug) cells $\left[F_{(1,16)}=1.06\right.$, $p=0.318]$. 

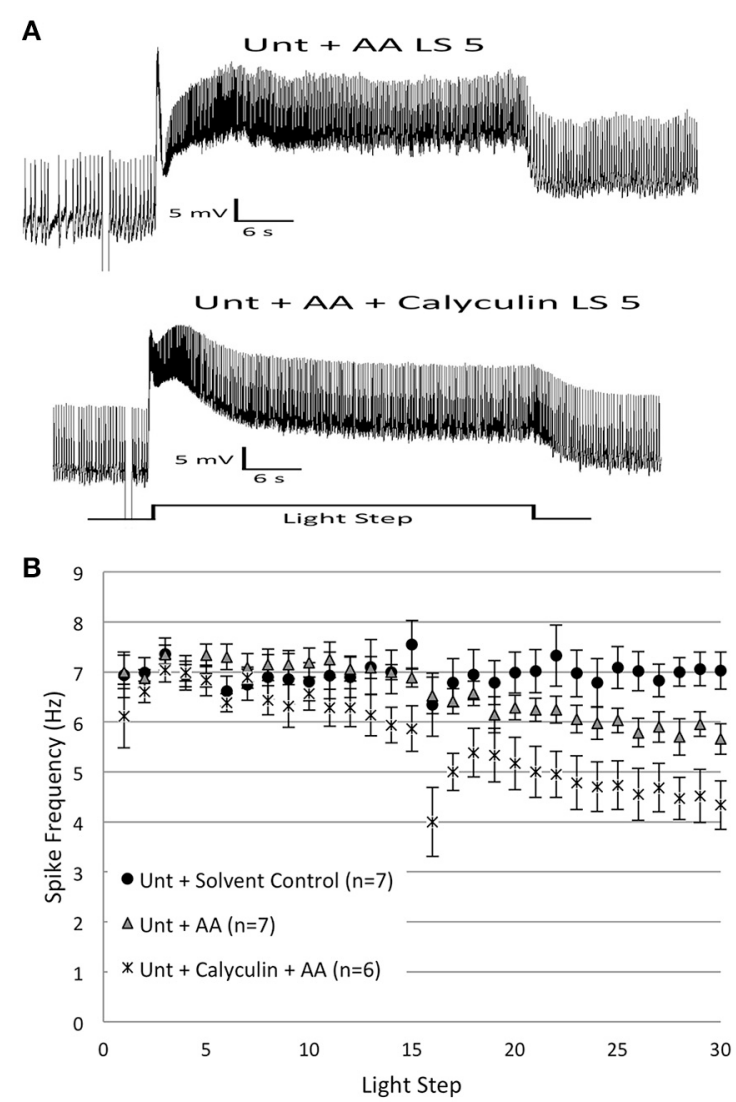

FIGURE 11 | Incubation of Untrained B cells in calyculin A (20 nM final bath concentration) enhanced the reduction in spike frequencies produced by arachidonic acid (AA; $100 \mu \mathrm{M}$ final bath concentration). (A) Representative light responses recorded from an Untrained Type B cell exposed to $\mathrm{AA}$ (Unt $+A A$; top trace) or calyculin followed by $\mathrm{AA}$ (Unt + Calyculin $+A A$; bottom trace). (B) Summary spike frequency data over 30 LSs of Type $B$ cells exposed to AA or calyculin. Unt $+A A$ cells exhibited decreases in spike frequencies compared to Unt + Solvent control cells (significant interaction between

Similar effects were observed when spike frequencies were analyzed as a percent change in spiking from the 5th to 30th LS. Untrained + Calyculin $+A A$ cells exhibited a $37.0 \pm 6.2 \%$ decrease in spike frequency that was significantly greater than Untrained + Calyculin cells $(10.8 \pm 12.5 \%$ increase $)\left[F_{(1,11)}=\right.$ 9.39, $p=0.011$ ] (Figure 11C), and Solvent controls (3.0 \pm $3.2 \%$ increase) $\left[F_{(1,11)}=20.60, p=0.001\right]$. The $37.0 \pm 6.2 \%$ decrease in spike frequency observed in Untrained + Calyculin + $A A$ cells was qualitatively, though not statistically, greater than Untrained $+A A$ cells $(23.0 \pm 4.1 \%$ decrease $)\left[F_{(1,11)}=3.82\right.$, $p=0.077]$, and was not significantly different from Paired (no drug) cells (33.5 $\pm 6.5 \%$ reduction) $\left[F_{(1,16)}=0.46, p=0.508\right]$.

In summary, calyculin failed to block the reduction in spike frequencies produced by AA, and instead enhanced the inhibitory effect of AA on spike frequency. These results indicate that the effects of AA are not mediated by PP1, and it seems unlikely that PP1 lies downstream from AA in B cell signaling pathways. However, it is possible that the reverse is true: activation of PP1 (by LSs and PP2B in Paired cells) might be critical for
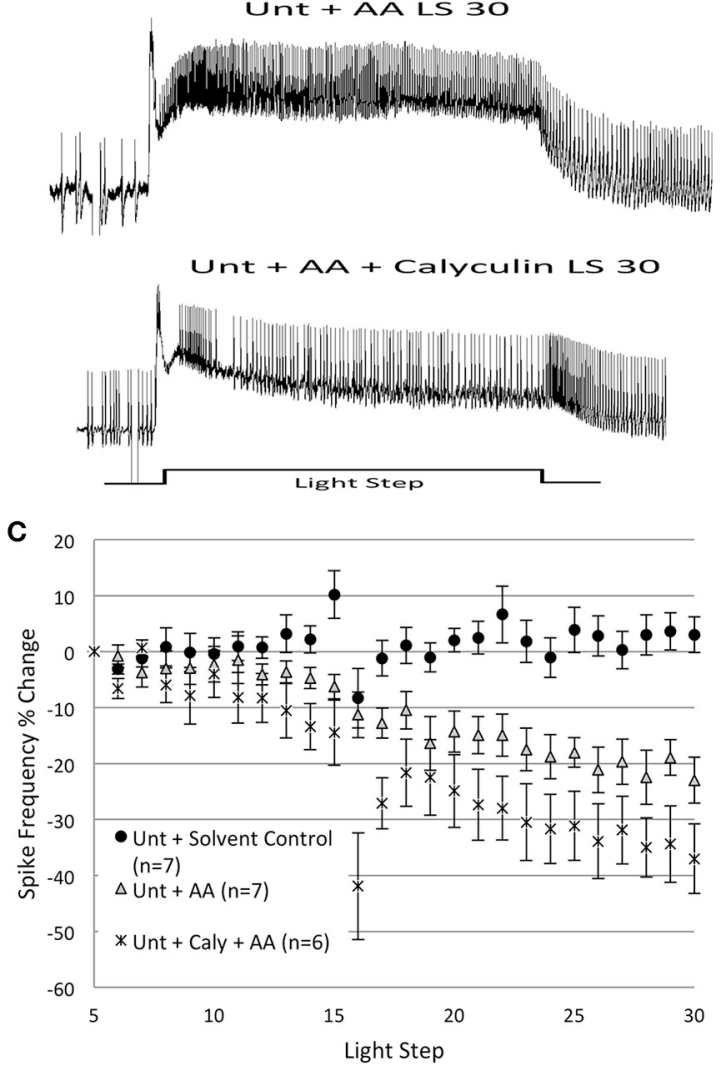

LS and condition). Unt + Calyculin $+A A$ cells showed decreases in spike frequencies that were significantly larger than the decreases observed in Unt $+A A$ cells. (C) Summary data of the relative percent change in B cell spike frequency from the 5th to 30th LS. Unt + Calyculin $+A A$ cells showed a large $37 \%$ decline in spike frequency that was significantly greater than the $\sim 3 \%$ increase seen in Unt + Solvent control cells, and qualitatively (though not statistically) larger than the $\sim 23 \%$ reduction observed in Unt $+A A$ cells. Error bars are \pm s.e.m. and significant $p$-values are $<0.05$.

synthesis/release of AA (and/or activity of 12-LOX). Our results suggest that there may also be an inhibitory interaction between the PP1- and AA-signaling pathways in B cells, because the combination of calyculin and AA led to greater decreases in spike frequencies than AA alone.

\section{DELAYED IN VITRO EXTINCTION FAILS TO PRODUCE REDUCTIONS IN SPIKE FREQUENCY}

Prior research has demonstrated that the interval between the end of learning acquisition and the beginning of extinction training can affect the outcome of extinction (Maren and Chang, 2006; Myers et al., 2006; Cavallo et al., 2014). Extinction training conducted shortly after associative conditioning can improve the effectiveness of extinction, and may even abolish the original associative memory (Mao et al., 2006; Myers et al., 2006; Monfils et al., 2009). In other circumstances, delayed extinction is more effective at producing lasting $\mathrm{CR}$ reduction without detectable evidence of the original memory (i.e., no spontaneous recovery) (Maren and Chang, 2006). 
To identify whether similar differences existed for extinction effectiveness in H.c., we repeated the in vitro extinction experiments using a prolonged $(24 \mathrm{~h})$ interval between original acquisition (light-rotation pairings) and the beginning of in vitro extinction. We hypothesized that memory consolidation processes would strengthen the memory for paired conditioning during the $24 \mathrm{~h}$ period after conditioning (Crow and Forrester, 1990; Epstein et al., 2003). Consequently, we expected that delayed in vitro extinction would produce smaller reductions in B cell spike frequencies (our cellular correlate of H.c. extinction) compared to more immediate (1-2 h) in vitro extinction. Thus, animals were given 2 days of paired conditioning followed by a $24 \mathrm{~h}$ interval (Paired 24- $h$ group), before receiving in vitro extinction (two sets of 15 LSs), using the same methodology as reported above. This longer interval is in contrast to the Paired group discussed above, which received in vitro extinction $1-2 \mathrm{~h}$ after the end of paired conditioning (referred to hereafter as the Paired 2- $h$ group).
During LSs 1-2, Paired 24- $h$ cells exhibited spike frequencies similar to that of Paired 2- $h$ cells. Thereafter, however, Paired 24- $h$ cells failed to exhibit the characteristic decrease in spiking observed in Paired 2- $h$ cells (Figures 12A-C) and had higher levels of spike frequencies during LSs 23-30 than Paired 2- $h$ cells. These results indicate that in vitro extinction was ineffective at altering B cell excitability when delayed by $24 \mathrm{~h}$.

During LSs 1-2, spike frequencies of Paired 24- $h$ cells $(n=7$, $7.23 \pm 0.27 \mathrm{~Hz})$ were greater than Untrained $(n=16,5.96 \pm$ $0.26 \mathrm{~Hz})$ control cells, and comparable to Paired $2-h$ cells $(n=11$, $7.44 \pm 0.31$; see Figure 2B), indicative of the enhanced excitability produced by associative learning (Farley and Alkon, 1982, 1987). An ANOVA compared the average spike frequencies during LSs 12 for Paired 24- $h$, Paired 2- $h$, and Untrained cells, and found a significant main effect of treatment condition $\left[F_{(2,31)}=8.66, p=\right.$ 0.001]. Post-hoc analysis revealed that both Paired 24- $h$ and Paired 2- $h$ cells spiked significantly more frequently than Untrained cells ( $p$ 's $=0.023,0.002$, respectively), but did not differ from each
A
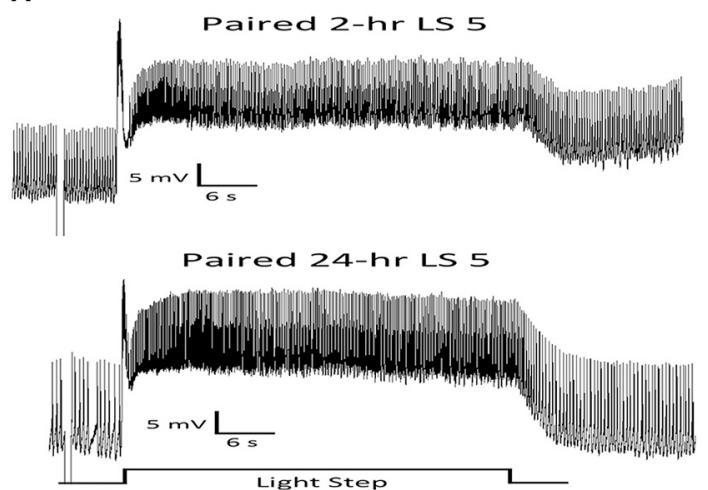

B

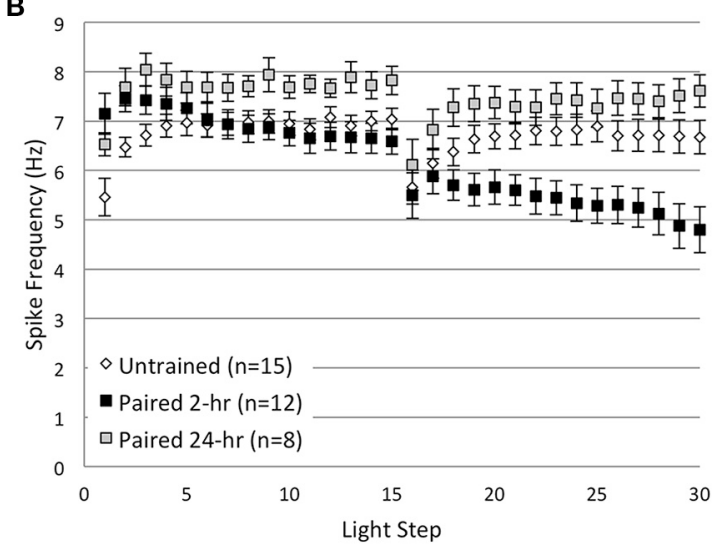

FIGURE 12 | Delayed in vitro extinction failed to reduce Type B cell spike frequencies. (A) Representative light responses recorded from Type B photoreceptors from paired-trained animals either $2 \mathrm{~h}$ (Paired 2-h; top trace) or $24 \mathrm{~h}$ (Paired $24-h$; bottom trace) after the end of paired conditioning. The Paired 24-h cell did not show any appreciable decline in spike frequency over the course of 30 LSs, while the Paired 2-h cell showed a significant decline. (B) Summary spike frequency data of Type B cells across 30 LSs from Untrained or Paired animals, both 2 and $24 \mathrm{~h}$ after conditioning. Paired 24-h cells showed increased spike frequencies compared to Untrained control and Paired 2-h cells during LSs 1-30, and
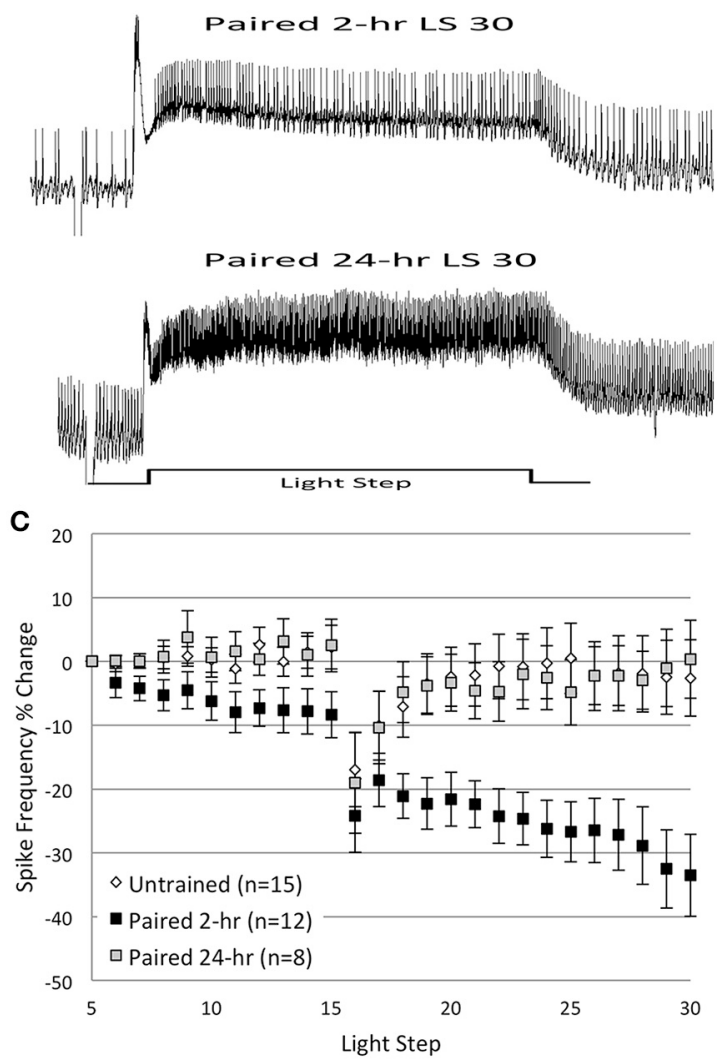

failed to show the progressive decrease in spike frequency exhibited by Paired 2-h cells. (C) Summary data of the percent change in B cell spike frequency from the 5th to 30th LS. Paired 24- $h$ cells showed no change $(\sim 0 \%)$ in spike frequency over the course of 30 LSs, which was indistinguishable from control cells ( $3 \%$ decrease), yet significantly different from the $\sim 34 \%$ spike frequency decrease exhibited by Paired $2-h$ cells. Error bars are \pm s.e.m. and significant $p$-values are $<0.05$. Note that one cell from each of the Paired $2-h$ and Paired $24-h$ groups was excluded from analysis during LSs $1-2$ due to missing spike frequency data as a result of electrode plugging. 
other $(p=1.0)$. After the first few LSs, spike frequencies of Paired $24-h$ cells were relatively constant and did not diminish with successive LSs, unlike Paired 2- $h$ cells (Figures 12A-C). Paired 24- $h$ cells showed enhanced rates of spiking throughout LSs 1-30 that were significantly greater than Untrained cells $\left[F_{(1,21)}=5.38\right.$, $p=0.030]$ (Figure 12B). Paired 24- $h(n=8)$ cells also showed significantly greater spike frequencies than Paired $2-h(n=12)$ cells over LSs $1-30\left[F_{(1,18)}=10.45, p=0.005\right]$, and failed to show the progressive decline in spike frequencies observed in Paired 2- $h$ cells as a result of repetitive LSs (Figure 12B).

Similar results were found when spike frequencies were analyzed as a percent change from the 5th to 30th LS. Paired $24-h$ cells showed little change in spike frequency during LSs 5-30 (0.4 \pm $6.1 \%$ decrease), which was significantly different from Paired 2- $h$ cells $(33.5 \pm 6.5 \%$ decrease $)\left[F_{(1,18)}=9.61, p=0.006\right]$, but not different from Untrained cells $(2.6 \pm 6.0 \%$ decrease $)\left[F_{(1,21)}=\right.$ $0.00, p=0.968$ ] (Figure 12C).

These results indicate that exposure of B cells to repeated LSs produced a large decrease in spike frequency when given to Paired cells relatively soon (1-2 h) after conditioning. Delaying this presentation by $24 \mathrm{~h}$ abolished the decrease in spike frequency produced by in vitro extinction.

\section{DISCUSSION}

\section{CELLULAR AND MOLECULAR CORRELATES OF EXTINCTION TRAINING}

The use of an in vitro extinction protocol allowed us to simulate whole-animal extinction in isolated H.c. nervous systems and investigate the cellular and molecular processes that occur during extinction training. Type B cells from paired-trained animals exposed to thirty successive LSs showed large (33.5\%) and progressive reductions in spike frequencies that were significantly below Untrained and non-associative control (Random) levels. These spike frequency reductions provided a striking correlate of whole-animal behavioral extinction (Cavallo et al., 2014), because they were contingent upon prior associative conditioning and only occurred when in vitro extinction was administered $1-2 \mathrm{~h}$, but not $24 \mathrm{~h}$, after paired conditioning. Our results implicated three molecules as participating in mediating the effects of in vitro extinction: PP1, PP2B, and AA/12(S)-HPETE.

\section{Protein phosphatase 1}

Three sets of experiments suggest that PP1 participates in the decline in spike frequency produced by in vitro extinction. First, incubation of B cells in the PP1 inhibitor, calyculin A, blocked the progressive spiking decrease in Paired cells, but had no significant effects in Untrained cells. We attribute this blocked reduction to PP1 inhibition, because although calyculin also inhibits PP2A (calyculin $\mathrm{IC}_{50}$ values of $0.5-1 \mathrm{nM}$ for PP2A vs. $2 \mathrm{nM}$ for PP1), several previous findings argue against any major role of PP2A. Huang and Farley (2001) found that cantharidic acid, a potent PP2A-selective inhibitor, had negligible effects on B cell excitability during in vitro associative conditioning, while both calyculin and inhibitor-1 had substantial impacts on cumulative depolarization and suppression of $\mathrm{K}^{+}$currents. Second, the injection of caPP1 into Untrained cells reduced spike frequencies by $20 \%$, which was not statistically different from the $33.5 \%$ decrease observed in Paired cells during in vitro extinction. Third, caPP1 injection into Paired cells reduced spike frequencies and occluded any further declines by in vitro extinction. This suggests that the declines in spiking elicited by repetitive LSs utilize PP1 signaling.

At least two alternative interpretations regarding the caPP1 results are possible. First, the spiking reductions during LSs 16-30 for Paired + PP1 cells might have reflected slow-to-develop effects of the enzyme itself, rather than effects triggered by LSs in Paired cells. From this perspective, exogenous caPP1 reduced spiking and occluded further reductions caused by repeated LSs. By this hypothesis, the latter effects arise from LS-induced activation of endogenous PP1. A second account views the reductions in spiking for Paired + PP1 cells resulting from effects of the LSs (just as for Paired cells), which then further occluded additional reductions due to injections of exogenous caPP1 (as occurred for Untrained $+P P 1)$. In both accounts, an occlusion between the effects of exogenous caPP1 and processes triggered by LSs is occurring, but it is unclear which is occluding which. Despite this uncertainty, the main point is clear. The reductions in spiking produced by caPP1 (in Untrained cells) and by LS-triggered processes (in Paired cells) are occurring in a common pathway in the case of Paired + PP1 cells. When combined, these reductions fail to add.

These results point toward PP1 signaling as being a critical pathway that mediates decreases in $\mathrm{B}$ cell excitability produced during in vitro extinction. Based on our prior work showing that PP1 enhances the same somatic $\mathrm{K}^{+}$channel currents reduced by associative conditioning (Huang and Farley, 2001), we posit that during in vitro extinction, PP1 reverses the cellular effects of paired conditioning through dephosphorylation of $\mathrm{K}^{+}$channels (or associated proteins) that are phosphorylated by PKC (Farley and Auerbach, 1986; Farley and Schuman, 1991) (see Figure 13).

\section{Protein phosphatase 2B}

Two findings argue for the involvement of $\mathrm{PP} 2 \mathrm{~B}$ signaling in the decreased excitability produced by in vitro extinction. First, incubation of B cells in the PP2B-specific inhibitor, cyclosporin A, prior to in vitro extinction completely blocked the large reduction in spiking elicited in Paired cells without drug, but did not significantly affect Untrained cells. Second, injection of caPP2B into Untrained cells elicited a $33.6 \%$ decrease in spiking that was essentially identical to the $33.5 \%$ decline observed during in vitro extinction in Paired cells. The caPP2B-produced spiking reduction in Untrained cells was dependent on PP1 activity, as it was blocked by the PP1 inhibitor calyculin A. This finding, combined with the fact that calyculin produced a similar block of spike frequency reductions in Paired cells, suggests that in Paired cells, PP2B activation acts upstream of PP1 to reduce B cell spiking during in vitro extinction.

One unexpected finding concerned the failure of $\mathrm{caPP} 2 \mathrm{~B}$ to reduce spiking when injected into Paired cells and to occlude any further declines in spike frequencies produced by repetitive LSs. This failure might be a consequence of injecting untargeted caPP2B into B cells, which might fail to dephosphorylate the substrates normally exposed to $\mathrm{PP} 2 \mathrm{~B}$ during in vitro extinction. We propose that endogenous $\mathrm{PP} 2 \mathrm{~B}$ is likely targeted to subcellular A-type $\mathrm{K}^{+}$-channel signaling complexes, through its associated regulatory subunit (Cohen, 1989), where it acts to 


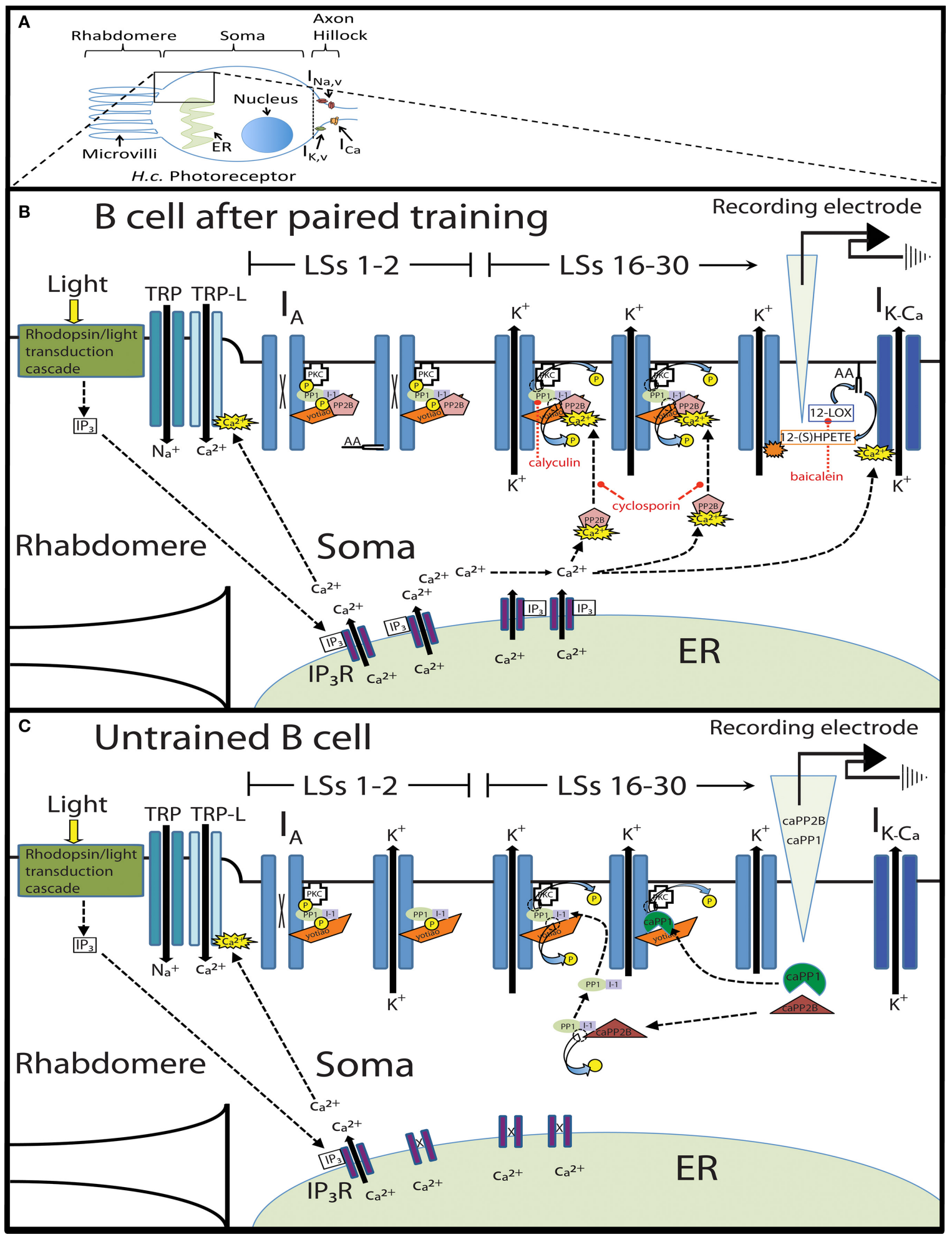

FIGURE 13 | Molecular model of a Paired and Untrained Type B cell given repeated light steps. (A) A cartoon illustration of a single Type $B$ photoreceptor with expanded view of the rhabdomere and soma subcellular regions. Note the three classes of voltage-dependent ion channels (sodium, potassium, and calcium) located in the axon hillock region (indicated by the dotted line). (B) Expanded view of a Type B cell 1-2 $\mathrm{h}$ after paired training. During light steps (LSs) 1-2 (left), many ( 30-50\%) of the somatic somatic $\mathrm{I}_{\mathrm{A}}$
$\mathrm{K}^{+}$channels are shut (indicated by an $\mathrm{X}$ in the channel pore) due to PKC-mediated phosphorylation of the channel itself or channel-associated proteins ( $\mathrm{P}$ indicates a phosphate group). Paired conditioning also mobilizes inhibitor-1/PP1 complexes and PP2B to $\mathrm{K}^{+}$channel signaling complexes, where both inactive phosphatases are localized via anchoring proteins such as yotiao/AKAP. Paired conditioning also activates $A A$, which facilitates the

(Continued) 


\section{FIGURE 13 | Continued}

phosphorylation of $\mathrm{K}^{+}$channel signaling complexes. The light-induced phototransduction cascade involving rhodopsin and a still unidentified G-protein coupled receptor (GPCR), results in the production of inositol trisphosphate $\left(\mathrm{IP}_{3}\right)$. Liberated $\mathrm{IP}_{3}$ subsequently activates $\mathrm{IP}_{3}$ receptors $\left(\mathrm{IP}_{3} \mathrm{Rs}\right)$ and releases $\mathrm{Ca}^{2+}$ from the endoplasmic reticulum (ER) into the cytosol. Paired conditioning leads to larger than normal light-induced $\mathrm{Ca}^{2+}$ release from the ER, and each successive LS (i.e., LSs 16-30) (right) releases a large amount of $\mathrm{Ca}^{2+}$ that favors the activation of PP2B. Activated PP2B disinhibits PP1 (through the dephosphorylation of inhibitor-1, 1-1), which is now able to dephosphorylate $\mathrm{K}^{+}$channels (or associated proteins), increase the activity of $I_{A}$ channels, and reduce $B$ cell spike frequency. The spike frequency reducing effects of PP2B and PP1 during the later LSs can be blocked by the inhibitors cyclosporin and calyculin, respectively (indicated by red dashed lines). Concurrent to the phosphatase-signaling pathway, repeated LSs also initiate 12-LOX activity, which metabolizes AA into 12(S)-HPETE. 12(S)-HPETE increases the activity of $\mathrm{I}_{\mathrm{A}} \mathrm{K}^{+}$channels, and possibly enhances the influx of $\mathrm{Ca}^{2+}$ via transient receptor potential-like (TRP-L) channels. Both of these processes further reduce $B$ cell excitability during LSs $16-30$. This reduced excitability might be further potentiated by greater activation of $I_{K-C a}$ via large $\mathrm{Ca}^{2+}$ release from the ER. (C) Expanded view of an Untrained Type $B$ cell during LSs 1-2 (left) and LSs 16-30 (right) injected with either catalytically active PP1 (caPP1) or PP2B (caPP2B). During the first two LSs, a certain fraction of somatic $\mathrm{K}^{+}$channels are phosphorylated via constitutively active PKC or other kinase(s), but most channels are not phosphorylated, resulting in the basal level of B cell excitability (i.e., lower than in Paired cells). Injection of caPP1 into Untrained B cells leads to the dephosphorylation of a certain fraction of phosphorylated $\mathrm{K}^{+}$channel signaling complexes (or associated proteins), enhancing $\mathrm{K}^{+}$channel activity, which reduces $B$ cell excitability below baseline levels during LSs 16-30. Similarly, injection of caPP2B disinhibits endogenous PP1, which eventually localizes to $\mathrm{K}^{+}$channel signaling complexes (via yotiao) and increases the activity of $\mathrm{I}_{\mathrm{A}} \mathrm{K}^{+}$channels, and reduces $\mathrm{B}$ cell spike frequency. Dotted arrows indicate direction of action, while solid arrows show ionic movement across a membrane through various ion channels. disinhibit PP1 (through inactivation of inhibitor-1) and reduce $\mathrm{B}$ cell excitability. In contrast, injection of exogenous caPP2B (without a regulatory subunit), might not preferentially associate with these $\mathrm{K}^{+}$-channel signaling complexes, and thus would fail to activate PP1. caPP2B might even dephosphorylate other targets that endogenous PP2B would not normally encounter [e.g., voltage-gated $\mathrm{Ca}^{2+}$ channels (Chad and Eckert, 1986)], and thereby oppose the reductions in $\mathrm{B}$ cell excitability produced by PP2B-mediated disinhibition of PP1.

In summary, our results suggest that PP2B is critically involved in the spike frequency reduction produced by in vitro extinction. PP2B may reduce B cell excitability through the disinhibition of PP1, and the subsequent dephosphorylation and opening of somatic $\mathrm{K}^{+}$channels, reversing learning-produced increases in excitability. This finding is reminiscent of work in rats indicating that PP2B mediates the extinction of conditioned fear responses and reverses the molecular processes (e.g., Akt kinase phosphorylation) associated with fear conditioning (Lin et al., 2003).

\section{Specificity of phosphatase inhibitors calyculin $A$ and cyclosporin $A$}

A legitimate issue in our use of calyculin and cyclosporin concerns the cross-species similarity of their intended protein phosphatase targets, and whether these inhibitors have similar substrate specificity in H.c. neurons. We believe the likelihood that these molecules exhibit similar functionality in H.c. is high for two reasons, (1) Biochemical analysis of phosphatases in invertebrate preparations, including starfish (Pondhaven and Cohen, 1987), Drosophila (Orgad et al., 1987), and Aplysia (Ichinose et al., 1990; Endo et al., 1995), indicate that their properties are remarkably similar to corresponding proteins in mammals (e.g., dephosphorylation of the beta subunit of phosphorylase kinase, $\mathrm{IC}_{50}$ values for inhibitors- 1 and -2, etc.), and (2) Genomic and crystallographic studies suggest striking conservation of phosphatase structures across species. For instance, genomic analyses indicate that the catalytic subunit of PP1 is one of the most conserved eukaryotic proteins (Ceulemans and Bollen, 2004; Shi, 2009), with $\sim 70 \%$ or greater protein sequence identity. Crystallographic studies of PP1 indicate that the active site is comprised of multiple calyculin-interaction regions, which prevent binding to downstream substrates (Lindvall et al., 1997; Kita et al., 2002). Thus, the highly conserved amino acid sequence and structure of PP1's active site make similar pharmacological and functional profiles for calyculin-produced inhibition of PP1 in H.c. neurons likely.

Cyclosporin has been used as an inhibitor of PP2B in numerous species (see Rühlmann and Nordheim, 1997 for review), ranging from yeast (Marton et al., 1998) to humans. The mechanism for cyclosporin's inhibition of PP2B has been extensively studied (Huai et al., 2002), and there appears to be strict conservation throughout all eukaryotes, such that all PP2B A genes encode for a polypeptide that distinguishes PP2B from other phosphatases. As with calyculin, it therefore seems unlikely that cyclosporin would have reliable effects in organisms as distant as yeast and humans, but not have noticeable effects in H.c. Although molecular identification and biochemical characterization of phosphatases from H.c. has not yet been accomplished, it seems highly likely that PP1 and PP2B were the major targets affected by calyculin and cyclosporin, respectively.

\section{Arachidonic acid and 12(S)-HPETE}

Three lines of evidence point to AA and 12(S)-HPETE as important contributors to the spike frequency decrease produced by in vitro extinction. First, baicalein, a specific 12-LOX enzyme inhibitor, blocked the spike frequency reduction observed in Paired cells, yet had no effect in Untrained cells. The 12-LOX enzyme is one of several intermediary enzymes that metabolize AA into second messenger molecules (Marks and Furstenberger, 1999). Our prior work in H.c. (Walker et al., 2010) found 12(S)HPETE to be a main AA metabolite mediating the B cell spiking decreases produced by both AA application and inhibitory conditioning.

The block of extinction-produced reductions in spike frequency by baicalein was somewhat surprising given the evident involvement of phosphatase-signaling pathways in H.c. extinction. Baicalein would not be expected to directly impact the activity of PP1 or PP2B, leaving the phosphatase-signaling pathway capable of activating $\mathrm{K}^{+}$channels and reducing spike frequencies. One possible explanation might be that baicalein indirectly interferes with the PP2B-PP1 pathway through the 
disruption of intracellular $\mathrm{Ca}^{2+}$ signaling that relies on $\mathrm{AA} / 12$ (S)HPETE to activate $\mathrm{Ca}^{2+}$ entry pathways, such as the transient receptor potential-like (TRP-L and/or TRP) (Chyb et al., 1999) and arachidonate-regulated $\mathrm{Ca}^{2+}$ (ARC) channels (Shuttleworth et al., 2004; Meves, 2008). Although the precise mechanism of this AA/12(S)-HPETE/phosphatase relationship is unclear, our novel finding that calyculin enhanced the reduction of spiking produced by AA in Untrained B cells supports the idea that both signaling pathways interact in a restrictive way.

The second finding that implicates AA/12(S)-HPETE involvement during in vitro extinction is that application of AA to Untrained cells elicited a progressive $23.0 \%$ reduction in spiking that mimicked the effects of in vitro extinction in Paired cells. This decrease was slightly (though not significantly) less than the 33.5\% decrease produced in Paired (no drug) cells during in vitro extinction, which might indicate that $\mathrm{AA} / 12(\mathrm{~S})$-HPETE is not the only molecule utilized during in vitro extinction, and/or that the pharmacokinetics of AA/12(S)-HPETE production are different for exogenous AA application vs. physiological stimulation. The AA-produced spiking decrease replicates prior research in H.c., which showed that application of AA or 12(S)-HPETE reduced spiking in Untrained B cells (Walker et al., 2010). Walker et al. (2010) also found that AA enhanced the transient $\mathrm{I}_{\mathrm{A}} \mathrm{K}^{+}$ current, the same current that is reduced following paired conditioning (Alkon et al., 1985; Farley, 1988a) and increased following inhibitory conditioning (Farley et al., submitted). Based on these findings, AA/12(S)-HPETE-produced increases in $\mathrm{I}_{\mathrm{A}} \mathrm{K}^{+}$currents are likely one mechanism that contributes to the reduction in $\mathrm{B}$ cell spiking during in vitro extinction (see Figure 13).

The third result that suggests AA/12(S)-HPETE is utilized during in vitro extinction is that the reduction in spike frequency produced by AA application to Paired cells occluded any further declines as a result of repeated LSs. This suggests that AA signaling and in vitro extinction share a common molecular pathway. Our previous experiments with AA (Walker et al., 2010) suggest that the AA-produced occlusion of additional spike frequency reductions observed here for Paired $+A A$ cells is unlikely to represent a "floor" effect in spike frequency reduction. Walker et al. (2010) found that the application of AA to B cells from inhibitoryconditioned animals produced an additional $\sim 22 \%$ reduction in spike frequency beyond that elicited by inhibitory conditioning alone. The somewhat smaller spiking reduction observed presently in Paired $+A A$ cells compared to Paired (no drug) cells might be a result of AA-produced enhancements of PKC activity (Lester et al., 1991), which could temporarily increase B cell excitability. This possibility was raised by Walker et al. (2010) to explain a brief elevation in B cell spike frequency produced by inhibitory conditioning, which dissipated $24 \mathrm{~h}$ later. We suggested that although AA metabolites like 12(S)-HPETE might reduce spiking over time, AA itself might transiently activate PKC and temporarily increase, rather than decrease, spiking (Walker et al., 2010). The present application of AA to Paired cells could have created a large fraction of non-metabolized AA that partially elevated $\mathrm{B}$ cell spiking through its facilitation of PKC and the resulting PKC-mediated reduction of $\mathrm{I}_{\mathrm{A}}$. Our baicalein results indicate, however, that in vitro extinction favors AA metabolism and the activity of 12(S)-HPETE.

\section{MOLECULAR MODEL OF EXTINCTION IN H.c.}

Collectively, our results support the conclusion that PP1, PP2B, and AA/12(S)-HPETE mediate reductions in B cell spike frequency produced by in vitro extinction. Here we propose a molecular model of extinction that incorporates this evidence into the broader body literature in H.c. (Figure 13). As previously proposed (Farley and Auerbach, 1986), paired conditioning activates PKC through the simultaneous release of two PKC cofactors, $\mathrm{Ca}^{2+}$ and diacylglycerol (DAG). $\mathrm{Ca}^{2+}$ release results primarily from a phototransduction cascade involving rhodopsin, phospholipase $\mathrm{C}$, and the production of inositol trisphosphate $\left(\mathrm{IP}_{3}\right)$ (Sakakibara et al., 1994), which activates $\mathrm{IP}_{3}$ receptors and releases $\mathrm{Ca}^{2+}$ from the endoplasmic reticulum into the cytosol, a process thought to be critical for learning-produced alterations of $\mathrm{K}^{+}$conductances and B cell excitability (Sakakibara et al., 1986). DAG production results from rotation-induced activation of G-protein coupled $\mathrm{GABA}_{B}$ and 5-HT receptors (see Blackwell and Farley, 2009 for review). Activated PKC is mobilized to the plasmamembrane where it reduces the activity of multiple classes of somatic $\mathrm{K}^{+}$channels (e.g., $\mathrm{I}_{\mathrm{A}}$ and $\mathrm{I}_{\mathrm{K}-\mathrm{Ca}}$ ), causing enhanced B cell excitability (Farley and Auerbach, 1986; Farley and Schuman, 1991). We suggest that endogenous PP1 is also localized to somatic $\mathrm{K}^{+}$channel signaling complexes, where it remains inactive due to inhibition by inhibitor-1. Rotation given during associative conditioning also stimulates the cleavage of AA from membrane phospholipids (via $G_{A B A}$ activation), which has been hypothesized to augment PKC effects and further enhance B cell excitability (Lester et al., 1991; Talk et al., 1997; Muzzio et al., 2001).

Shortly (1-2 h) after paired conditioning (Figure 13A), in vitro extinction (repeated LSs) elicits larger than normal increases in cytosolic $\mathrm{Ca}^{2+}$ (Ito et al., 1994). We suggest that elevated intracellular $\mathrm{Ca}^{2+}$ preferentially activates PP2B due to PP2B's high affinity for $\mathrm{Ca}^{2+}$ compared to PKC (Lisman, 1989), and saturation of PKC signaling. Activated PP2B aggregates near PP1-containing $\mathrm{K}^{+}$channel complexes through regulatory subunit targeting (e.g., yotiao/AKAP), where it dephosphorylates inhibitor-1 and relieves PP1 inhibition (Mulkey et al., 1994). Enzymatically active PP1 is now able to enhance the activity of A-type $\mathrm{K}^{+}$channels and reduce B cell spiking. Exposure to cyclosporin or calyculin after paired conditioning blocks this phosphatase-signaling pathway and prevents in vitro extinction from reducing $B$ cell spike frequencies. Concurrent with the PP2B-PP1 signaling pathway, AA is metabolized by the 12-LOX enzyme into 12(S)-HPETE, which further reduces $B$ cell excitability through enhancements of $I_{A}$. The mechanism by which 12-LOX is activated by repeated LSs in Paired cells is presently unknown.

Our experiments using catalytically active phosphatases (caPP1 and caPP2B) into Untrained B cells are congruent with this model (Figure 13B). Injection of caPP2B into Untrained cells might dephosphorylate a large fraction of cytosolic inhibitor-1/PP1 complexes that have not been mobilized to the membrane. Once dephosphorylated, activated PP1 anchors to stabilizing proteins (e.g., yotiao) and dephosphorylates $\mathrm{K}^{+}$ channel signaling-complexes (or associated proteins). Injection of caPP1 into Untrained B cells has similar, but less robust, effects on $\mathrm{K}^{+}$channel activity. Although caPP1 is able to dephosphorylate a 
certain percentage of $\mathrm{K}^{+}$channel signaling-complexes (or associated proteins), we suggest that the lack of a regulatory subunit prevents localization to $\mathrm{K}^{+}$channel signaling-complexes, and therefore results in less dephosphorylation.

In contrast to in vitro extinction given shortly after associative conditioning, delayed in vitro extinction did not decrease B cell spike frequencies. Two possible explanations present themselves. First, $24 \mathrm{~h}$ after associative conditioning, repeated LSs might activate PP2B, PP1, and AA/12(S)-HPETE, but their ability to reduce spike frequencies (through enhancements of $\mathrm{I}_{\mathrm{A}}$ ), is counteracted and overshadowed by persistent, constitutive PKC activity (Farley and Schuman, 1991), which suppresses $\mathrm{I}_{\mathrm{A}}$ and increases cell excitability, thus preventing reductions in spike frequencies. Second, perhaps phosphatases are unable to significantly impact $B$ cell spiking during delayed in vitro extinction because phosphatase-signaling effects are restricted to a relatively brief critical period after paired conditioning. Although numerous mechanisms could create the conditions for such a critical period, one possibility is that phosphatase activation shortly after paired conditioning disrupts the consolidation of associative memories by regulating the activity of cAMP response elementbinding protein (CREB) (Silva et al., 1998), which could inhibit additional synthesis of PKC necessary for producing the behavioral changes indicative of long-term associative memories in H.c. (Alkon et al., 2005).

\section{RELATIONSHIP TO EXTINCTION IN OTHER SYSTEMS}

Our evidence indicates that PP1, PP2B, and AA/12(S)-HPETE all participate in the in vitro extinction-produced reduction of $\mathrm{B}$ cell spiking. Therefore, these molecules are likely candidates for mediating the cellular changes in excitability that accompany the extinction-produced reversal of phototactic suppression. Not surprisingly, there are precedents for involvement of these same (or closely-related) signaling pathways in extinction of memories in other systems.

For example, a similar bi-directional modification of $\mathrm{K}^{+}$channels by PKC/PKA and PP1 is believed to underlie short-term facilitation and depression of sensory-motor neuron synaptic transmission in Aplysia (Braha et al., 1990; Sugita et al., 1994; Endo et al., 1995). Additionally, in rat hippocampal CA1 neurons, PP1 reduces synaptic transmission during the induction of some forms of long-term depression (LTD) of synaptic transmission (Morishita et al., 2001). This could be one mechanism by which PP1 facilitates extinction of conditioned taste aversion in rats (Oberbeck et al., 2010) and promotes memory decline during water maze tasks in mice (Genoux et al., 2002). PP1 also constrains learning during short-interval (i.e., massed) associative training in mice (Genoux et al., 2002) and H.c. (Muzzio et al., 1999). To our knowledge, neither AA nor 12-LOX metabolites have been implicated in extinction learning in other (vertebrate) systems. However, related fatty acids in the endocannabinoid signaling system are believed to be important contributors to extinction. Cannabinoid (CB) receptors and their endogenous ligands, endocannabinoids, have been reported to participate in extinction of memory for aversive events in rats (Marsicano et al., 2002; Cannich et al., 2004). Despite the detection of endocannabinoids in Aplysia ganglia (Di Marzo et al., 1999), and other invertebrates (e.g., leech, Stefano et al., 1997), their existence in other invertebrate species is still debated (McPartland et al., 2006), and their role in learning has yet to be determined. Nevertheless, it is possible that AA/LOX-metabolites and associated ion channels (TRP and $\mathrm{K}^{+}$channels) may be invertebrate evolutionary precursors to the endocannabinoid system of vertebrates, and play similar functional roles.

A final point concerns the fact that in vitro extinction reduced Paired B cell spiking below the levels of Untrained and Random control cells. If a simple reversal/erasure of the pairing-produced changes in cell excitability were occurring, then one might expect the spike frequencies of Paired cells to be indistinguishable from control cells during later LSs. However, in vitro extinction produced a pairing-specific decrease in spiking that was clearly lower than control cells by the 30th LS. The lower spike frequency of Paired cells is reminiscent of the persistent reductions in B cell spiking produced by CI learning (Britton and Farley, 1999). In conjunction with the common involvement of PP1 and AA/12(S)HPETE in both CI and extinction, the in vitro results suggest that extinction may reflect "new" CI-like learning, although it is unclear whether the in vitro-produced reductions in spike frequency persist for $24 \mathrm{~h}$. The view that the original molecular substrates of associative memories are completely "erased," and the nervous system returned to its original de novo state by extinction training, may be overly simplistic. A more nuanced view of cellular and behavioral erasure effects by extinction might be that a new, possibly dynamic, equilibrium (between opposing original acquisition, "new" extinction learning, and erasure processes) is established following extinction training. Therefore, the original associatively-acquired behavioral changes could appear absent due to overall circuit level alterations, but changes at the scale of individual neurons (and subcellular alterations) might persist and reflect varying combinations of old and new learning mechanisms. Whether extinction in H.c. produces a complete erasure of the original associative memory might depend on the level of analysis (i.e., behavior, circuit, or individual neuron). Although it is a convenient heuristic to organize research efforts around mutual exclusive categories of extinction learning (i.e., erasure or new learning), this tendency could be overly simplistic and should not blind us to the inherit complexity of extinction learning.

\section{ACKNOWLEDGMENTS}

This research was supported by a grant from the National Institute of Neurological Disorders and Stroke (NIH NIDS NS48156). We thank Claude Klee for her gift of PP2B, and Katie Babcock and Sally Miller for their invaluable assistance with this research. Finally we would like to thank Tony Walker for his intellectual contributions to this project and for his general support.

\section{REFERENCES}

Alkon, D. L., Epstein, H., Kuzirian, A., Bennett, M. C., and Nelson, T. J. (2005) Protein synthesis required for long-term memory is induced by PKC activation on days before associative learning. Proc. Natl. Acad. Sci. U.S.A. 102, 16432-16437. doi: 10.1073/pnas.0508001102

Alkon, D. L., Sakakibara, M., Forman, R., Harrigan, J., Lederhendler, I., and Farley, J. (1985). Reduction of two voltage-dependent $\mathrm{K}^{+}$currents mediates retention of a learned association. Behav. Neural Biol. 44, 278-300. doi: 10.1016/S01631047(85)90296-1

Bader, C. R., Baumann, F., and Bertrand, D. (1976). Role of intracellular calcium and sodium in light adaptation in the retina of the honey 
bee drone (Apis mellifera). J. Gen. Physiol. 67, 475-491. doi: 10.1085/jgp. 67.4.475

Baumgärtel, K., Genoux, D., Welzl, H., Tweedie-Cullen, R. Y., Koshibu, K., Liningstone-Zatchej, M., et al. (2008). Control of the establishment of aversive memory by calcineurin and Zif268. Nat. Neurosci. 11, 572-578. doi: $10.1038 / \mathrm{nn} .2113$

Blackwell, K., and Farley, J. (2009). Hermissenda. Scholarpedia 3, 4090-4095. doi: 10.4249/scholarpedia.4090

Bouton, M. E. (1994). Conditioning, remembering, and forgetting. J. Exp. Psychol. Anim. Behav. Process. 20, 219-231. doi: 10.1037/0097-7403.20.3.219

Braha, O., Dale, N., Hochner, B., Klein, M., Abrams, T. W., and Kandel, E. R. (1990). Second messengers involved in the two processes of presynaptic facilitation that contribute to sensitization and dishabituation in Aplysia sensory neurons. Proc. Natl. Acad. Sci. U.S.A. 87, 2040-2044. doi: 10.1073/pnas.87.5.2040

Britton, G., and Farley, J. (1999). Behavioral and neural bases of non-coincidence learning in Hermissenda. J. Neurosci. 19, 9126-9132.

Cannich, A., Wotjak, C. T., Kamprath, K., Hermann, H., Lutz, B., and Marsicano, G. (2004). CB1 cannabinoid receptors modulate kinase and phosphatase activity during extinction of conditioned fear in mice. Learn. Mem. 11, 625-632. doi: $10.1101 / \mathrm{lm} .77904$

Cavallo, J. S., Hamilton, B., and Farley, J. (2014). Behavioral and neural bases of extinction learning in Hermissenda. Front. Behav. Neurosci. 8:277. doi: 10.3389/fnbeh.2014.00277

Ceulemans, H., and Bollen, M. (2004). Functional diversity of protein phosphatase1, a cellular economizer and reset button. Physiol. Rev. 84, 1-39. doi: 10.1152/physrev.00013.2003

Chad, J. E., and Eckert, R. (1986). An enzymatic mechanism for calcium current inactivation in dialysed helix neurons. J. Physiol. 378, 31-51.

Chyb, S., Raghu, P., and Hardie, R. C. (1999). Polyunsaturated fatty acids activate the Drosophila light-sensitive channels TRP and TRPL. Nature 397, 255-259. doi: $10.1038 / 16703$

Clem, R. L., and Huganir, R. L. (2010). Calcium-permeable AMPA receptor dynamics mediate fear memory erasure. Science 330, 1108-1112. doi: 10.1126/science.1195298

Cohen, P. (1989). The structure and regulation of protein phosphatases. Annu. Rev. Biochem. 58, 453-508. doi: 10.1146/annurev.bi.58.070189.002321

Crow, T. (2004). Pavlovian conditioning of Hermissenda: current cellular, molecular, and circuit perspectives. Learn. Mem. 11, 229-238. doi: 10.1101/lm.70704

Crow, T., and Forrester, J. (1990). Inhibition of protein synthesis blocks long-term enhancement of generator potentials produced by one-trial in vivo conditioning in Hermissenda. Proc. Natl. Acad. Sci. U.S.A. 87, 4490-4494. doi: 10.1073/pnas.87.12.4490

Di Marzo, V., De Petrocellis, L., Bisogno, T., and Melck, D. (1999). Metabolism of anandamide and 2-arachidonoylglycerol: an historical overview and some recent developments. Lipids 34, S319-S325. doi: 10.1007/BF02562332

Duerson, K., White, R. E., Jiang, F., Schonbrunn, A., and Armstrong, D. L. (1996). Somatostatin stimulates BK Ca channels in rat pituitary tumor cells through lipoxygenase metabolites of arachidonic acid. Neuropharmacology 35, 949-961. doi: 10.1016/0028-3908(96)00131-1

Endo, S., Critz, S. D., Byrne, J. H., and Shenolikar, S. (1995). Protein phosphatase1 regulates outward $\mathrm{K}^{+}$currents in sensory neurons of Aplysia californica. J. Neurochem. 64, 1833-1840. doi: 10.1046/j.1471-4159.1995.64041833.x

Epstein, H. T., Child, F. M., Kuzirian, A. M., and Alkon, D. L. (2003). Time windows for effects of protein synthesis inhibitors on Pavlovian conditioning in Hermissenda: behavioral aspects. Neurobiol. Learn. Mem. 79, 127-131. doi: 10.1016/S1074-7427(02)00020-5

Farley, J. (1987a). Contingency learning and causal detection in Hermissenda: I. Behavior. Behav. Neurosci. 101, 13-27. doi: 10.1037/0735-7044.101.1.13

Farley, J. (1987b). Contingency learning and causal detection in Hermissenda: II. Cellular mechanisms. Behav. Neurosci. 101, 28-56. doi: 10.1037/07357044.101.1.28

Farley, J. (1988a). Associative training results in persistent reductions in a calciumactivated potassium current in Hermissenda Type B photoreceptors. Behav. Neurosci. 102, 784-801. doi: 10.1037/0735-7044.102.5.784

Farley, J. (1988b). "Causal detection in a mollusc: cellular mechanisms of predictive coding, associative learning and memory," in Harvard Symposium on Quantitative Analyses of Behavior: Vol. 7, Biological Determinants of Reinforcement, eds M. Commons, R. Church, J. Stellar, and A. Wagner (New Jersey, NJ: Lawrence Erlbaum Associates, Inc.), 207-248.
Farley, J., and Alkon, D. L. (1980). Neural organization predicts stimulus specificity for a retained associative behavioral change. Science 210, 1373-1375. doi: 10.1126/science.7434033

Farley, J., and Alkon, D. L. (1982). Associative neural and behavioral change in Hermissenda: consequences of nervous system orientation for light and pairing specificity. J. Neurophysiol. 48, 785-807.

Farley, J., and Alkon, D. L. (1987). In vitro associative conditioning of Hermissenda: cumulative depolarization of Type B photoreceptors and short-term associative behavioral changes. J. Neurophysiol. 57, 1639-1668.

Farley, J., and Auerbach, S. (1986). Protein kinase C activation induces conductance changes in Hermissenda photoreceptors like those seen in associative learning. Nature 319, 220-223. doi: 10.1038/319220a0

Farley, J., Richards, W. G., Ling, L. J., Liman, E., and Alkon, D. L. (1983). Membrane changes in a single photoreceptor cause associative learning in Hermissenda. Science 221, 1201-1203. doi: 10.1126/science.6612335

Farley, J., and Schuman, E. (1991). Protein kinase C inhibitors prevent induction and continued expression of cell memory in Hermissenda type B photoreceptors. Proc. Natl. Acad. Sci. U.S.A. 88, 2016-2020. doi: 10.1073/pnas.88.5.2016

Fruman, D., Klee, C., Bierer, B., and Burakoff, S. (1992). Calcineurin phosphatase activity in T lymphocytes is inhibited by FK 506 and cyclosporin A. Proc. Natl. Acad. Sci. U.S.A. 89, 3686-3690. doi: 10.1073/pnas.89.9.3686

Genoux, D., Haditsch, U., Knobloch, M., Michalon, A., Storm, D., and Mansuy, I. M. (2002). Protein phosphatase 1 is a molecular constraint on learning and memory. Nature 418, 970-975. doi: 10.1038/nature00928

Goh, Y., Lederhendler, I., and Alkon, D. L. (1985). Input and output changes of an identified neural pathway are correlated with associative learning in Hermissenda. J. Neurosci. 5, 536-543.

Grover, L. M., and Farley, J. (1987). Temporal order sensitivity of associative learning in Hermissenda: behavior and neural correlates. Behav. Neurosci. 101, 658-675. doi: 10.1037/0735-7044.101.5.658

Havekes, R., Nijholt, I. M., Visser, A. K., Eisel, U. L., and Van der Zee, E. A. (2008). Transgenic inhibition of neuronal calcinuerin activity in the forebrain facilitates fear conditioning, but inhibits the extinction of contextual fear. Neurobiol. Learn. Mem. 89, 595-598. doi: 10.1016/j.nlm.2007.08.003

Huai, Q., Kim, H. Y., Liu, Y., Zhao, Y., Mondragon, A., Liu, J. O., et al. (2002). Crystal structure of calcineurin-cyclophilin-cyclosporin shows common but distinct recognition of immunophilin-drug complexes. Proc. Natl. Acad. Sci. U.S.A. 99, 12037-12042. doi: 10.1073/pnas.192206699

Huang, H., and Farley, J. (2001). PP1 Inhibitors depolarize Hermissenda photoreceptors and reduce $\mathrm{K}^{+}$currents. J. Neurophysiol. 86, 1297-1311.

Ichinose, M., Endo, S., Critz, S. D., Shenolikar, S., and Byrne, J. H. (1990). Microcystein-LR, a potent protein phosphatase inhibitor, prolongs the serotonin- and cAMP-induced currents in sensory neurons of Aplysia californica. Brain Res. 533, 137-140. doi: 10.1016/0006-8993(90)91806-R

Ito, E., Oka, K., Collin, C., Schreurs, B. G., Sakakibara, M., and Alkon, D. L. (1994). Intracellular calcium signals are enhanced for days after Pavlovian conditioning. J. Neurochem. 62, 1337-1344. doi: 10.1046/j.1471-4159.1994.62041337.x

Jin, I., Huang, H., Smith, B., and Farley, J. (2009). Protein tyrosine kinase involvement in learning-produced changes in Hermissenda Type B photoreceptors. J. Neurophysiol. 102, 3573-3595. doi: 10.1152/jn.90732.2008

Kita, A., Matsunaga, S., Takai, A., Kataiwa, H., Wakimoto, T., Fusetani, N., et al. (2002). Crystal structure of the complex between calyculin A and the catalytic subunit of protein phosphatase 1. Structure 10, 715-724. doi: 10.1016/S09692126(02)00764-5

Lederhendler, I. I., Gart, S., and Alkon, D. L. (1986). Classical conditioning of Hermissenda: origin of a new response. J. Neurosci. 6, 1325-1331.

Lester, D. S., Collin, C., Etcheberrigaray, R., and Alkon, D. L. (1991). Arachidonic acid and diacylglycerol act synergistically to activate protein kinase C in vitro and in vivo. Biochem. Biophys. Res. Commun. 179, 1522-1528. doi: 10.1016/0006-291X(91)91745-X

Lin, C., Yeh, S., Leu, T., Chang, W., Wang, S., and Gean, P. (2003). Identification of calcineurin as a key signal in the extinction of fear memory. J. Neurosci. 23, 1574-1579

Lindvall, M. K., Pihko, P. M., and Koskinen, A. M. (1997). The binding mode of calyculin A to protein phosphatase-1, a novel spiroketal vector model. J. Biol. Chem. 272, 23312-23316. doi: 10.1074/jbc.272.37.23312

Lisman, J. (1989). A mechanism for the Hebb and anti-Hebb processes underlying learning and memory. Proc. Natl. Acad. Sci. U.S.A. 86, 9574-9578. doi: 10.1073/pnas.86.23.9574 
Lisman, J., and Brown, J. (1972). The effects of intracellular iontophoretic injection of calcium and sodium ions on the light response of Limulus ventral photoreceptors. J. Gen. Physiol. 59, 701-719. doi: 10.1085/jgp.59.6.701

Mao, S. C., Hsiao, Y. H., and Gean, P. W. (2006). Extinction training in conjunction with partial agonist of the glycine site on the NMDA receptor erases memory trace. J. Neurosci. 26, 8892-8899. doi: 10.1523/JNEUROSCI.036506.2006

Maren, S., and Chang, C. H. (2006). Recent fear is resistant to extinction. Proc. Natl. Acad. Sci. U.S.A. 21, 18020-18025. doi: 10.1073/pnas.0608398103

Marks, F., and Furstenberger, G. (1999). Prostaglandins, Leukotrienes and Other Eicosanoids: From Biogenesis to Clinical Application. Weinhein: Wiley-VCH.

Marsicano, G., Wotjak, C. T., Azad, S. C., Bisogno, T., Rammes, G., and Grazia Cascio, M. (2002). The endogenous cannabinoid system controls extinction of aversive memories. Nature 418, 530-534. doi: 10.1038/nature00839

Marton, M. J., DeRisi, J. L., Bennett, H. A., Iyer, V. R., Meyer, M. R., Roberts, C. J., et al. (1998). Drug target validation and identification of secondary drug target effects using DNA microarrays. Nat. Med. 4, 1293-1301. doi: 10.1038/3282

McPartland, J. M., Agraval, J., Gleeson, D., Heasman, K., and Glass, M. (2006). Cannabinoid receptors in invertebrates. J. Evol. Biol. 19, 366-373. doi: 10.1111/j.1420-9101.2005.01028.x

Meves, H. (2008). Arachidonic acid and ion channels: an update. Br. J. Pharmacol. 155, 4-16. doi: 10.1038/bjp.2008.216

Monfils, M. H., Cowansage, K. K., Kall, E., and LeDoux, J. E. (2009). Extinctionreconsolidation boundaries: key to persistent attenuation of fear memories. Science 324, 951-955. doi: 10.1126/science.1167975

Morishita, W., Connor, J. H., Xia, H., Quinlan, E. M., Shenolikar, S., and Malenka, R. C. (2001). Regulation of synaptic strength by protein phosphatase 1 . Neuron 32, 1133-1148. doi: 10.1016/S0896-6273(01)00554-2

Mulkey, R. M., Endo, S., Shenolikar, S., and Malenka, R. C. (1994). Involvement of calcineurin/inhibitor 1 phosphatase cascade in hippocampus long-term depression. Nature 369, 486-488. doi: 10.1038/369486a0

Muzzio, I. A., Gandhi, C. C., Manyam, U., Pesnell, A., and Matzel, L. D. (2001). Receptor-stimulated phospholipase A(2) liberates arachidonic acid and regulates neuronal excitability through protein kinase C. J. Neurophysiol. 85, 1639-1647.

Muzzio, I. A., Ramirez, R. R., Talk, A. C., and Matzel, L. D. (1999). Interactive contributions of intracellular calcium and protein phosphatases to massedtrails learning deficits in Hermissenda. Behav. Neurosci. 113, 103-117. doi: 10.1037/0735-7044.113.1.103

Myers, K. M., and Davis, M. (2002). Behavioral and neural analysis of extinction. Neuron 36, 567-584. doi: 10.1016/S0896-6273(02)01064-4

Myers, K. M., Ressler, K. J., and Davis, M. (2006). Different mechanisms of fear extinction dependent on length of time since fear acquisition. Learn. Mem. 13, 216-223. doi: 10.1101/lm.119806

Oberbeck, D. L., McCormack, S., and Houpt, T. A. (2010). Intra-amygdalar okadaic acid enhances conditioned taste aversion learning and CREB phosphorylation in rats. Brain Res. 1348, 84-94. doi: 10.1016/j.brainres.2010. 06.029

Orgad, S., Dudai, Y., and Cohen, P. (1987). The protein phosphatases of Drosophila melanogaster and their inhibitors. Eur. J. Biochem. 164, 31-38. doi: 10.1111/j.1432-1033.1987.tb10988.x

Pavlov, I. P. (1927). Conditioned Reflexes. London: Oxford University Press.

Pondhaven, P., and Cohen, P. (1987). Identification of protein phosphatases1 and $2 \mathrm{~A}$ and inhibitor-2 in oocytes of the starfish Asterias rubens and Marthasterias glacialis. Eur. J. Biochem. 167, 135-140. doi: 10.1111/j.14321033.1987.tb13314.x

Rescorla, R. A., and Cunningham, C. L. (1978). Recovery of the US representation over time during extinction. Learn. Motiv. 9, 373-391. doi: 10.1016/00239690(78)90001-2

Rescorla, R. A., and Heth, C. D. (1975). Reinstatement of fear to an extinquished conditioned stimulus. J. Exp. Psychol. Anim. Behav. Process. 1, 88-96. doi: 10.1037/0097-7403.1.1.88

Resjö, S., Oknianska, A., Zolnierowicz, S., Manganiello, V., and Degerman, E. (1999). Phosphorylation and activation of phosphodiesterase type 3B (PDE3B) in adipocytes in response to serine/threonine phosphatase inhibitors: deactivation of PDE3B in vitro by protein phosphatase type 2A. J. Biochem. 341, 839-845. doi: 10.1042/0264-6021:3410839

Richards, W., and Farley, J. (1987). Motor correlates of phototaxis and associative learning in Hermissenda crassicornis. Brain Res. Bull. 19, 175-189. doi: 10.1016/0361-9230(87)90083-9
Richards, W., Farley, J., and Alkon, D. (1984). Extinction of associative learning in Hermissenda: behavior and neural correlates. Behav. Brain Res. 14, 161-170. doi: 10.1016/0166-4328(84)90185-2

Robbins, S. J. (1990). Mechanisms underlying spontaneous recovery in autoshaping. J. Exp. Psychol. Anim. Behav. Process. 16, 235-249. doi: 10.1037/00977403.16.3.235

Rühlmann, A., and Nordheim, A. (1997). Effects of the immunosuppressive drugs CsA and FK506 on intracellular signaling and gene regulation. Immunobiology 198, 192-206. doi: 10.1016/S0171-2985(97)80040-X

Sakakibara, M., Alkon, D. L., Kouchi, T., Inoue, H., and Yoshioka, T. (1994) Induction of photoresponse by the hydrolysis of polyphosphoinositides in the Hermissenda Type B photoreceptor. Biochem. Biophys. Res. Commun. 202, 299-306. doi: 10.1006/bbrc.1994.1927

Sakakibara, M., Alkon, D. L., Neary, J. T., Heldman, E., and Gould, R. (1986). Inositol trisphosphate regulation of photoreceptor membrane currents. Biophys. J. 50, 797-803. doi: 10.1016/S0006-3495(86)83520-2

Sangha, S., Scheibenstock, A., Morrow, R., and Lukowiak, K. (2003). Extinction requires new RNA and protein synthesis and the soma of the cell right pedal dorsal 1 in Lymnaea stagnalis. J. Neurosci. 23, 9842-9851.

Schiller, D., Monfils, M. H., Raio, C. M., Johnson, D. C., LeDoux, J. E., and Phelps, E. A. (2010). Preventing the return of fear in humans using reconsolidation update mechanisms. Nature 463, 49-53. doi: 10.1038/nature08637

Sharma, K., Bagnall, M. W., Sutton, M. A., and Carew, T. J. (2003). Inhibition of calcineurin facilitates the induction of memory for sensitization in Aplysia: requirement of mitogen-activated protein kinase. Proc. Natl. Acad. Sci. U.S.A. 100, 4861-4866. doi: 10.1073/pnas.0830994100

Shi, Y. (2009). Serine/threonine phosphatases: mechanism through structure. Cell 139, 468-484. doi: 10.1016/j.cell.2009.10.006

Shuttleworth, T. J., Thompson, J. L., and Mignen, O. (2004). ARC channels: a novel pathway for receptor-activated calcium entry. Physiology 19, 355-361. doi: 10.1152/physiol.00018.2004

Silva, A. J., Kogan, J. H., Frankland, P. W., and Kida, S. (1998). CREB and memory. Annu. Rev. Neurosci. 21, 127-148. doi: 10.1146/annurev.neuro.21.1.127

Stafstrom-Davis, C. A., Ouimet, C. C., Feng, J., Allen, P. B., Greengard, P., and Houpt, T. A. (2001). Impaired conditioned taste aversion learning in spinophilin knockout mice. Learn. Mem. 8, 272-278. doi: 10.1101/lm.42101

Stefano, G. B., Salzet, B., Rialas, C. M., Pope, M., Kustka, A., Neenan, K., et al. (1997). Identification and characterization of the leech CNS cannabinoid receptor: coupling to nitric oxide release. Brain Res. 753, 219-224. doi: 10.1016/S0006-8993(96)01484-9

Stemmer, P. M., and Klee, C. B. (1994). Dual calcium ion regulation of calcineurin by calmodulin and calcineurin B. Biochemistry 33, 6859-6866. doi: 10.1021/bi00188a015

Sugita, S., Baxter, D. A., and Byrne, J. H. (1994). Activators of protein kinase $\mathrm{C}$ mimic serotonin-induced modulation of a voltage-dependent potassium current in pleural sensory neurons of Aplysia. J. Neurophysiol. 72, 1240-1249.

Talk, A. C., Muzzio, I. A., and Matzel, L. D. (1997). Phospholipases and arachidonic acid contribute independently to sensory transduction and associative neuronal facilitation in Hermissenda type B photoreceptors. Brain Res. 751, 196-205. doi: 10.1016/S0006-8993(96)01397-2

Walker, T. L., Campodonico, J., Cavallo, J. S., and Farley, J. (2010). AA/12lipoxygenase signaling contributes to inhibitory learning in Hermissenda type B photoreceptors. Front. Behav. Neurosci. 4:50. doi: 10.3389/fnbeh.2010.00050

Conflict of Interest Statement: The authors declare that the research was conducted in the absence of any commercial or financial relationships that could be construed as a potential conflict of interest.

Received: 06 May 2014; accepted: 23 September 2014; published online: 21 October 2014.

Citation: Cavallo JS, Hamilton BN and Farley J (2014) In vitro extinction learning in Hermissenda: involvement of conditioned inhibition molecules. Front. Behav. Neurosci. 8:354. doi: 10.3389/fnbeh.2014.00354

This article was submitted to the journal Frontiers in Behavioral Neuroscience. Copyright (c) 2014 Cavallo, Hamilton and Farley. This is an open-access article distributed under the terms of the Creative Commons Attribution License (CC BY). The use, distribution or reproduction in other forums is permitted, provided the original author(s) or licensor are credited and that the original publication in this journal is cited, in accordance with accepted academic practice. No use, distribution or reproduction is permitted which does not comply with these terms. 